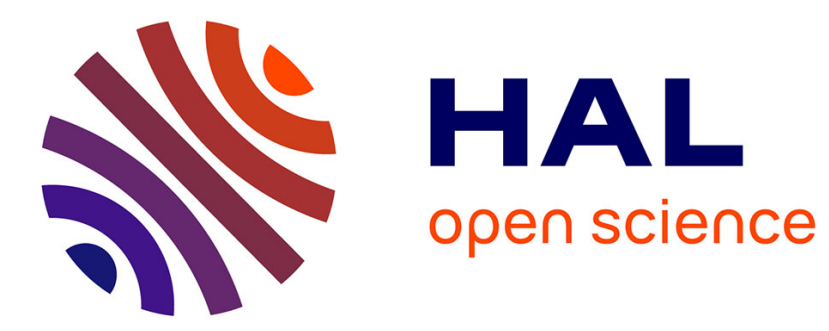

\title{
Les revendications paysannes collectives dans le Midi portugais (1275-1385)
}

Stéphane Boissellier

\section{To cite this version:}

Stéphane Boissellier. Les revendications paysannes collectives dans le Midi portugais (1275-1385).

Histoire et sociétés rurales, 2001, 15 (1), pp.165-192. 10.3917/hsr.015.0165 . halshs-00734263

\section{HAL Id: halshs-00734263 \\ https://shs.hal.science/halshs-00734263}

Submitted on 6 Feb 2017

HAL is a multi-disciplinary open access archive for the deposit and dissemination of scientific research documents, whether they are published or not. The documents may come from teaching and research institutions in France or abroad, or from public or private research centers.
L'archive ouverte pluridisciplinaire HAL, est destinée au dépôt et à la diffusion de documents scientifiques de niveau recherche, publiés ou non, émanant des établissements d'enseignement et de recherche français ou étrangers, des laboratoires publics ou privés. 


\title{
LES REVENDICATIONS PAYSANNES COLLECTIVES DANS LE MIDI PORTUGAIS (1275-1385)
}

Stéphane Boissellier

\author{
Association d'histoire des sociétés rurales (A.H.S.R.)| "Histoire \& Sociétés
}

Rurales »

2001/1 Vol. 15 | pages 165 à 192

ISSN 1254-728x

ISBN encours

Article disponible en ligne à l'adresse :

http://www.cairn.info/revue-histoire-et-societes-rurales-2001-1-page-165.htm

\section{Pour citer cet article :}

Stéphane Boissellier, « Les revendications paysannes collectives dans le Midi portugais (1275-1385) », Histoire \& Sociétés Rurales 2001/1 (Vol. 15), p. 165-192.

Distribution électronique Cairn.info pour Association d'histoire des sociétés rurales (A.H.S.R.).

(C) Association d'histoire des sociétés rurales (A.H.S.R.). Tous droits réservés pour tous pays.

La reproduction ou représentation de cet article, notamment par photocopie, n'est autorisée que dans les limites des conditions générales d'utilisation du site ou, le cas échéant, des conditions générales de la licence souscrite par votre établissement. Toute autre reproduction ou représentation, en tout ou partie, sous quelque forme et de quelque manière que ce soit, est interdite sauf accord préalable et écrit de l'éditeur, en dehors des cas prévus par la législation en vigueur en France. Il est précisé que son stockage dans une base de données est également interdit. 


\title{
LES REVENDICATIONS PAYSANNES COLLECTIVES DANS LE MIDI PORTUGAIS (I275-I385)
}

Stéphane BOISSELLIER*

\begin{abstract}
Résumé : Au sud du Portugal, l'étude des revendications collectives paysannes revêt de profondes spécificités, sur les deux plans, historique et documentaire : les communautés naissent (sous une organisation municipale ou incluse dans un municipe) d'une convergence d'intérêts entre les groupes de colons et les autorités légales. Jusqu'au milieu du XIII siècle, les conflits se règlent dans un processus coutumier qui laisse peu de traces explicites. Ensuite, la prise en main seigneuriale devient plus rigoureuse, notamment sur le plan financier, et les conflits prennent une forme procédurale : on observe alors des communautés encore assez homogènes (malgré une évolution vers l'oligarchie politique et la concentration foncière) et donc combatives, mais obligées de s'intégrer dans les objectifs et les mécanismes du pouvoir monarchique pour préserver leurs intérêts.
\end{abstract}

Mots clés : communautés rurales, justice, Portugal, revendications paysannes, seigneurie.

Abstract : In the South of Portugal, the study of peasant claims reveals strong particularities, both historically and from a documentary point of view: The rural communities (organized in municipal concelhos) were born from a convergence of interests uniting the colonists and the legal authorities. Up to around I250, conflicts were solved through customary negociations which left few explicit references. Later, seignorial control was strengthened for financial reasons, and conflicting claims were translated into legal proceedings. It becomes possible to observe the communities in more details. They turn out to be still largely homogeneous (in spite of a clear trend toward political oligarchy and land concentration), hence their continued combativity; but they were increasingly compelled to insert themselves within a monarchic system in order to defend their interests.

Key words : justice, manor, peasant claims, Portugal, rural communities.

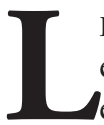

ES SOURCES MÉDIÉVALES sont pleines de conflits (généralement non armés) entre paysans et seigneurs; quoique interprétés comme preuve de faiblesse et de l'incapacité des paysans à s'organiser face aux potentes ou exaltés en tant qu'appui «démocratique » à la construction de l'État, ces litiges sont en fait un facteur capital dans la constitution et l'évolution des communautés rurales; du point de vue de l'historien, un élément particulièrement intéressant peut être retenu dans ces conflits, c'est l'expression de l'opinion publique locale.

Toutefois, la région évoqu ée dans les documents qui suivent - le Portugal au sud du Tage - présente des spécificités assez marquées pour poser une problématique inhabituelle; en effet, dans le but d'obtenir toutes les prestations militaires possibles, les seigneurs y organisent d'emblée la colonisation dans le cadre de municipes largement autonomes mais sous leur contrôle assez étroit. C'est dire

\footnotetext{
* Maître de conférences en histoire médiévale à l'Université de Tours, UFR Arts et Sciences humaines, 3, rue des Tanneurs, BP 4I03,3704I Tours cedex I (e-mail: boissell@club-internet.fr).
} 
que, contrairement au mouvement communal du Nord du Portugal (à Porto) et d'autres régions septentrionales de l'Occident chrétien, plus conforme au " modèle " féodal (anti-seigneurial) classique, les revendications paysannes méridionales ne visent jamais le partage du pouvoir mais sont un instrument de régulation de son exercice. Certes, les premiers temps des concelhos "primitifs", entre II47 et I2IO, nous échappent largement ; une nouvelle étude des chartes municipales (forais) serait à entreprendre pour déterminer les rapports de force exacts entre le personnel colonial et les maîtres du ban et l'on pourrait probablement alors intégrer ces chartes elles-mêmes parmi les canaux d'expression d'une libération de la seigneurie directe; toujours est-il que, quand commencent à nous parvenir les échos des revendications rurales, le modèle municipal s'est largement imposé et a cantonné la seigneurie directe quasiment dans les seuls rapports fonciers.

La riche tradition portugaise d'études du phénomène municipal est longtemps restée centrée sur les institutions et a utilisé le contenu concret des revendications pour analyser la structuration et les intérêts des différentes catégories sociales au sein des municipes ou, tout simplement, les activités économiques; les sources présentées ici ont l'intérêt d'éclairer le fonctionnement des communautés municipales, dans leurs rapports avec les seigneurs politiques (qui en sont les créateurs, au moins sur le plan légal).

\section{Un type documentaire tardif}

Dans le Sud portugais, les documents exprimant des revendications (sans être encore toujours des documents ad hoc) n'apparaissent clairement qu'à partir des années I250-I270. C'est principalement le système judiciaire de l'appel (monopole monarchique en ce qui concerne l'appel en dernière instance - sauf évidemment pour les ecclésiastiques - puis toute forme d'appel à partir de I280I290) qui fait des revendications communautaires ${ }^{1}$ une catégorie juridique, même si cette uniformisation laisse subsister une grande variété diplomatique (notice de plaid, pièce originale de procédure ou d'arbitrage, notice intégrée dans les " actes " de Cortes ou dans une enquête).

À cette époque, dans la grande majorité des communautés méridionales (qui sont sous seigneurie du roi), la première et dernière instance judiciaire est la monarchie, à travers ses diverses formes (cf. le bel exposé de procédure dans la source IO2), ou même dans une relation immédiate (source 97 présentant une communauté maure, sous dépendance très directe du monarque, qui plus est dans le cadre d'un domaine reguengo, où la justice est exercée par les administrateurs seigneuriaux et non par des juges élus - comme c'est aussi le cas avec l'almoxarife de la source Ior mais par abus de pouvoir). Cependant il existe des

1. Les revendications individuelles, elles, ne sont conservées que quand elles passent par la voie contentieuse et constituent donc à ce titre, depuis toujours, une catégorie juridique parfaitement déterminée dans le cadre de la procédure judiciaire (source 97). 
seigneuries non monarchiques ${ }^{2}$ dans lesquelles le parcours des plaintes jusqu'au roi s'effectue probablement à plusieurs niveaux, au moins en ce qui concerne la voie contentieuse, notamment dans les domaines des Ordres militaires, qui constituent une organisation administrative hiérarchisée; les demandes exprimées en Cortes sont, elles, évidemment directes puisque c'est une des raisons d'être de cette institution.

Mais les voies d'expression non contentieuses se développent parallèlement. L'intégration de représentants des principales communautés d'habitants (municipes) dans les Cortes, à partir de I254, crée un instrument d'expression solennel et centralisateur (demandes, dites "chapitres", adressées au roi par des communautés mais aussi au nom du "peuple», source I04), qui réduit considérablement le recours à la voie contentieuse en matière d'administration seigneuriale (i.e. seigneurie royale), et permet au monarque d'instituer un lien direct avec tous ses sujets (même ceux sous juridiction "étrangère»); ces plaintes, quoique assez terre à terre et ponctuelles, expriment plus ou moins explicitement des conceptions réfléchies de la société mais, à ce titre, leur formulation est largement médiatisée par les élites les plus savantes des communautés.

La procédure inquisitoire (source I03) facilite grandement l'expression des revendications paysannes et les monarques portugais s'en sont faits les spécialistes, avec les plus anciennes enquêtes générales d'Europe comme celles d'Afonso II, en I220; elle constitue un véritable instrument d'administration et de réforme du droit. Là où leur juridiction est bien établie, les monarques l'utilisent assez peu, disposant d'autres moyens pour dialoguer avec leurs hommes (surtout quand ceux-ci sont organisés en communautés organiques), et ces deux facteurs expliquent que les enquêtes soient rares et tardives dans l'entre Tage et Guadiana, province "municipalisée» et bien contrôlée par les monarques; en revanche, l'enquête, suscitant les revendications autant qu'elle y répond, peut être avant tout un moyen d'action contre les autres seigneurs : celle qui est diligentée dans la source I03, sous couvert d'un recensement du patrimoine foncier de la Couronne, est utilisée, si ce n'est conçue, pour imposer le recours royal dans une zone de faible implantation monarchique. Le principal problème de telles sources n'est pas tant l'orientation du questionnaire par les enquêteurs que le caractère individualiste des préoccupations exprimées par les témoins.

2. Il s'agit de zones théoriquement concédées par le monarque (dans une formule diplomatique et juridique plus proche de la donation foncière sans restriction que du fief), bien que l'on ne conserve pas toujours l'acte de transfert du dominium; les cas de seigneuries créées hors du contrôle monarchique, notamment sur une base foncière, sont rares, obscurs quant à l'origine juridique du ban, mais de toute façon sans effets majeurs pour l'exercice du pouvoir sur les sujets (voir Stéphane BOISSELLIER, "Des franchises aux coutumes : la formation et l'évolution du prélèvement seigneurial (l'exemple d'Évora II65-I280) ", in Pascual MARTINEZ SOPENA et Monique Bourin, (dir.), Pour une anthropologie du prélèvement seigneurial dans les campagnes de l'Occident médiéval (XI'-XIVe siècles). Réalités et représentations paysannes du prélèvement Actes du colloque (ValladolidMedina del Campo, 3 I mai-4 juin 200o), Paris, Presses de la Sorbonne, 20or [à paraître]. 
Les voies légales d'expression de revendications collectives ${ }^{3}$ qui apparaissent dans le dossier sont : l'envoi direct de plaintes au seigneur (mais les documents conservés dans ce cas sont seulement monarchiques) ${ }^{4}$, l'appel en Cour royale dans le cadre d'une procédure (type documentaire le plus courant), la demande de confirmation de franchises et usages (en fait rétablissement de ces droits), le présentation de "chapitres" en Cortes (qui ne reçoivent que les revendications en matière administrative) ${ }^{5}$, mise à profit de la présence d'enquêteurs pour exprimer des plaintes ${ }^{6}$.

Dans les périodes antérieures à I250 (c'est-à-dire à partir de II5O dans le Midi portugais, début de la pénétration chrétienne dans le Sud), en l'absence d'enquêtes, on n'a presque aucune trace explicite de revendications, soit parce qu'elles se règlent par compromis direct ou par arbitrage sans traces écrites conservées, soit parce que l'absence d'enregistrement en chancellerie nous prive des appels judiciaires (cette dernière explication, strictement archivistique, étant plus improbable car les actes royaux antérieurs à la constitution des registres de chancellerie sont généralement assez bien conservés, notamment dans les originaux et copies conformes de la collection dite des "Gavetas»). Il est également possible que, avant I250, dans les zones politiques non monarchiques, la monarchie ne réussisse pas à s'imposer comme instance d'appel; mais cela semble improbable en vertu du principe selon lequel, dans les zones de conquête sur l'Islam, tout pouvoir émane du roi ou, au moins, remonte jusqu'à lui : le dispositif très rudimentaire des chartes de délégation des regalia suppose - sans jamais la formuler explicitement - la juridiction monarchique suprême des contentieux (ainsi que l'organisation des sujets en communauté organique, les deux éléments étant liés).

3. La source 97 implique une personne privée et n’a été intégrée dans le dossier qu'en vertu de son ancienneté.

4. Quand il s'agit d'un seigneur ayant des intérêts dans tout le Portugal, l'itinérance du monarque, qui perdure longtemps après la fixation d'une "capitale " à Lisbonne (pour la période qui nous occupe), facilite le contact entre seigneur et sujets; la présence du roi en personne dans le municipe plaignant (Santarém) n'a probablement pas de signification dans la source Ioo - il s'agit d'une affaire de longue haleine, jugée en instance suprême - mais elle joue certainement un rôle dans la source Ior (où la formule diplomatique révèle un contact direct).

5. En fait, la source IO4 est le procès-verbal d'une session d'une assemblée municipale préparant des "articles" à intégrer dans les chapitres présentés par le municipe aux prochaines Cortes; quoiqu'il ne soit pas inédit, nous avons préféré produire ce document exceptionnel plutôt que des chapitres eux-mêmes, ceci parce que les "actes" conservés des Cortes (d'ailleurs publiés de façon systématique à partir du règne d'Afonso IV, I325-I357) ne sont pas les procès-verbaux des sessions - reprenant intégralement les plaintes - mais les arrêts royaux correspondants et parce que les «actes» antérieurs (Cortes d'Afonso III et Dinis, I245-I325), inédits, sont conservés sous forme de chartes royales particulières (significativement intégrées dans la série d'archives dite «Suplemento de Cortes"), sans caractère systématique et dont les rapports avec la session des Cortes ne sont pas toujours clairs (elles sont à rapprocher du recours direct auprès du seigneur).

6. Comme le document évoqué dans la note précédente, cette enquête (source I03) n’est pas inédite mais constitue un moyen d'expression des revendications suffisamment original pour être présenté ici. 


\section{Les origines des communautés, leurs revendications et l'usage du droit}

Que la légalisation des revendications communautaires soit tardive dans le Midi est un fait révélateur des origines des communautés. L'absence de révolte connue montre que les canaux informels (coutumiers) puis légaux d'expression sont longtemps suffisants pour obtenir gain de cause; comme partout ailleurs en Occident, même après l'institution des Cortes "générales" (intégrant des représentants du peuple), de nombreux droits obtenus par les communautés (notamment sous la forme la plus systématique, les chartes de franchises) le sont par transaction ou jugement et revêtent à ce titre la forme du privilège (unilatéral), y compris quand ils émanent d'une procédure tranchée par la Curia regis (et les actes de Cortes conservent longtemps le caractère diplomatique d'une collection de privilèges particuliers, enregistrés seulement au coup par coup dans les livres de chancellerie) : on touche là au difficile problème des conditions d'obtention des franchises. On peut supposer que les revendications (de l'élite roturière, les cavaliers villageois) jouent un rôle moteur dans l'obtention du statut municipal (enjeu essentiel dans la région) et de nombreuses autres "franchises" par la communauté; mais, dans un cadre essentiellement coutumier, ce sont alors tous les documents émanant des rapports avec l'autorité de tutelle, même les plus anodins, qui peuvent être lus comme une expression ou au moins comme le résultat de revendications auprès du seigneur ${ }^{7}$ : cette difficulté d'interprétation nous a fait exclure ces documents anciens.

L'émergence de canaux de revendications mieux adaptés et la multiplication des plaintes elles-mêmes - cela impliquant partiellement ceci - à partir des années I250 peuvent s'expliquer par la relative inefficacité de la transaction coutumière face à un seigneur décidé, notamment quand il s'agit du monarque, de mieux en mieux servi par une administration et des légistes ; en effet, la coutume, qui fonde la légitimité de la demande, doit être prouvée, ce qui exige quelques moyens et l'unanimité communautaire. Plutôt que d'être toujours en retard d'un combat, il est tentant pour les élites politiques municipales - qui se définissent de mieux en mieux au sein des communautés, en particulier grâce à la direction des luttes - d'aller sur le terrain des seigneurs et d'obtenir décrets ou jugements, si ponctuels soient-ils, au lieu d'accords oraux et sans formulation juridique rigoureuse, simples statu quo qu'il faudra 30 ou 40 ans pour transformer en norme juridique; la source IoI montre clairement l'inefficacité de la "force d'inertie» coutumière employée par une communauté pourtant populeuse et dynamique - et la promesse de non-aliénation de la juridiction tutélaire à une seigneurie non monarchique finira par être intégrée dans les chartes de franchise postérieures.

7. Cf. les amendements à la charte municipale (ou foral) de II79, obtenus par le concilium de Santarém vers IIgo (Portugaliae monumenta historica. Leges et consuetudines, I, éd. A. HerCulano, (dir.), Lisbonne, 1856, p. 409); analyse diplomatique détaillée du document dans Rui Pinto de AZEVEDO, "Um problema histórico ainda mal esclarecido por insuficiência de estudo diplomático ", in Académia portuguesa de História. Dois centenários, Lisbonne, 196I, p. 63-95. 
Le fait que les revendications soient souvent prises en compte par l'autorité implique - au-delà des intérêts en jeu - une bonne connaissance du droit par les plaignants puisqu'elles se fondent sur des notions juridiques de légitimité et légalité (la source 99 emploie le vocable "desaforamento", la source ior l'expression "per força»); cette connaissance vient de ce que la création juridique est largement coutumière et locale, émanant des mécanismes sociaux et impliquant notamment les élites locales (juges et officiers). Ce ne sont donc pas seulement des opérations de "lobbying" communautaire purement égoïstes aux dépens d'une autre communauté ou contre le seigneur.

On notera aussi que le cadre des revendications est toujours municipal ou «semi-municipal» (cas particulier et obscur des domaines seigneuriaux reguengos) - les rares communautés totalement inorganiques n'ont pas de voies légales d'expression laissant des traces documentaires - et que les revendications sont présentées comme unanimes; ceci est une nécessité pour que les demandes soient efficaces car un groupe juridique légal peut seul être pris en compte (contrairement aux groupes sociaux fondés sur l'intérêt, sans consistance juridique). Ce cadre d'expression pose le problème de la notion même de municipe : la grande majorité des sites d'habitat ruraux sont englobés dans un territoire municipal sans détenir leur propre charte et subissent donc une juridiction de la part du chef-lieu (site ayant reçu la charte municipale) ${ }^{8}$; certaines communautés sans charte propre ont suffisamment d'autonomie pour formuler leurs propres plaintes (source 99, Messejana village dépendant d'Aljustrel) mais on ne sait pas qui est représenté quand l'action est menée par le chef-lieu : tous les villages du territoire municipal ou le seul chef-lieu? Dans la source IO4, la liste des membres de l'assemblée, à l'exception de João Gonçalves dit "de Ludo" - petit hameau du territoire municipal - n'inclut que des "homens da dicta vila» de Loulé, vila ayant le sens d'agglomération chef-lieu.

Les voies d'expression légales des intérêts collectifs ne sont de toute façon conçues que pour exprimer des intérêts au niveau d'un village (le cas le plus évident étant celui des Cortes, où les plaintes sont largement ritualisées), c'est-à-dire les conflits contre le seigneur ou contre une autre communauté; les seuls individus ou groupes pouvant faire l'objet de revendications jouissent d'un statut (officiers et communautés maures, source 98). En effet, un principe fondateur des municipes est la non-intervention d'une entité extérieure, et notamment du seigneur légitime (le mieux placé pour intervenir à la moindre occasion), dans les affaires internes (à savoir ne relevant pas des rapports avec le seigneur); ceci explique que même les «sous-groupes» jouissant d'un statut légal au sein des

8. Dans la source I03, la mise à profit de la présence d'enquêteurs royaux pour se plaindre du seigneur n'est pas liée à l'inorganicité de la communauté (Almodôvar, d'abord dans la zone juridictionnelle du castrum de Marachique, possède sa propre charte depuis I285), mais s'explique par la peur d'entreprendre une action ouverte contre un commandeur particulièrement brutal ou par le fait que c'est seulement une partie de la population (donc un groupe sans existence juridique) qui est atteinte. 
municipes (piétons et chevaliers) ne s'expriment jamais explicitement en tant que tels et que les conflits entre communautés apparaissent moins souvent dans la documentation que les plaintes contre les seigneurs politiques. À l'inverse, les communautés refusent de se mêler des affaires menées par leur seigneur, même quand elles pourraient y avoir un intérêt; ainsi le municipe d'Avis est capable de mener une longue et lourde procédure (source IO2) contre son seigneur, l'Ordre militaire du même nom, mais il n'intervient pas dans le litige avec le municipe de Santarém (source Ioo).

\section{Carte I.}

Les communautés contestataires au sud du Portugal (XIII'-XIVe siècle)

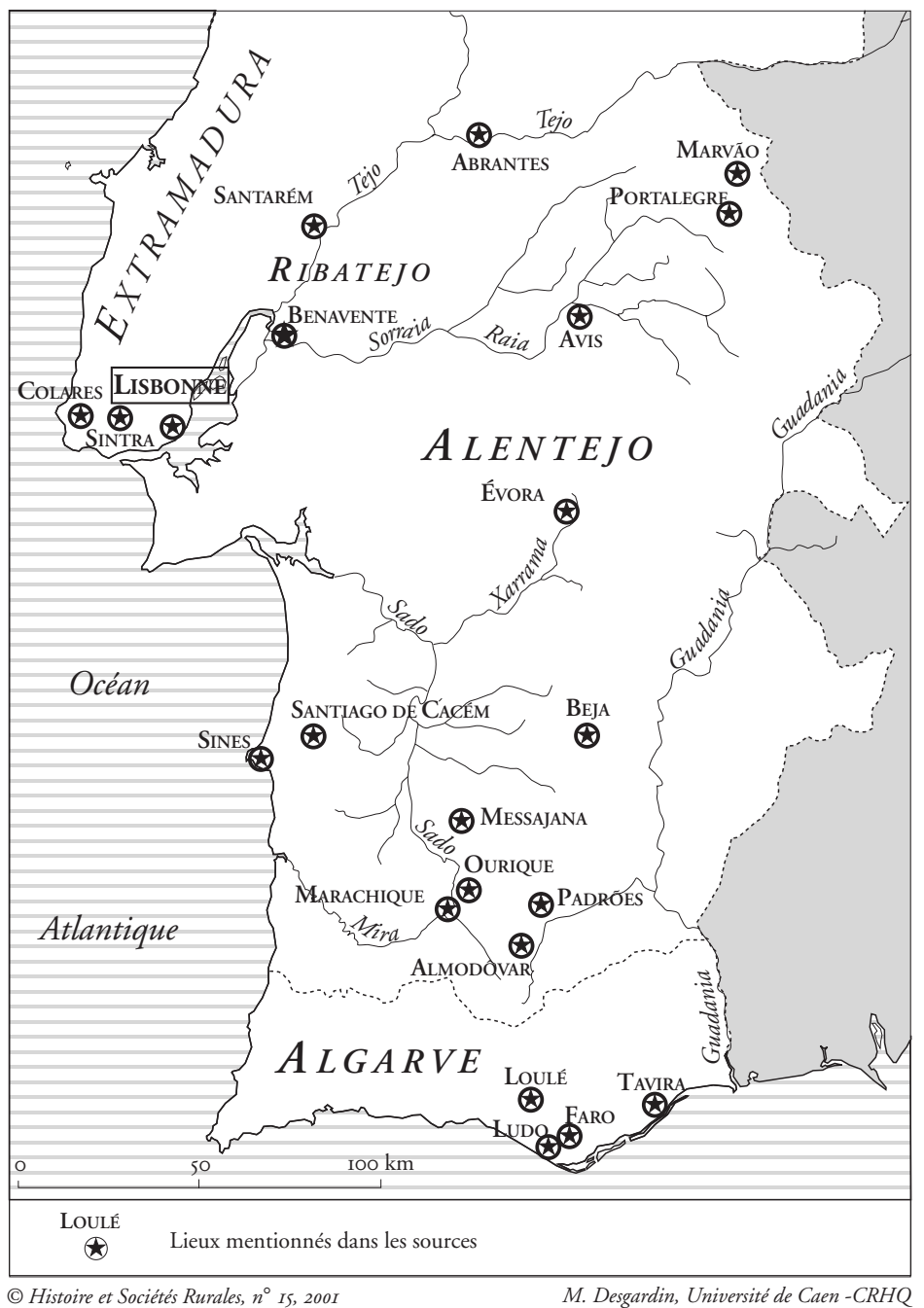




\section{L'objet des revendications et les enjeux}

Les revendications ne sont pas seulement passives (réactions à la modification d'une situation établie ou à un mauvais usage du pouvoir de gestion) mais expriment aussi les initiatives paysannes des évolutions, dans le domaine du droit positif (ainsi les demandes d'autonomie juridictionnelle par rapport à leur village-mère de la part des villages ayant grossi, comme le village de Sines par rapport à son chef-lieu Santiago do Cacém en 1362). Les documents retenus mettent en scène surtout des abus administratifs seigneuriaux en matière de prélèvement sur le travail et les revenus (croit de cens dans la source 98, abus du banvin dans la source 99, élargissement des limites municipales pour accroître dîmes et droits d'usage dans la source Ioo, surencadrement pénal dans la source IoI, saisies abusives dans les sources IO2 et IO3), ce qui s'explique par la date tardive des documents ; une fois terminée la phase active de la Reconquête (I250), le service armé offert par les sujets perd de son intérêt - c'est vrai dès les années I22O-I23O, avec l'implication croissante des Ordres militaires - et les seigneurs orientent leur ponction vers ce qu'ils offrent désormais de plus précieux, la production de biens et de services en travail.

En dépit du dynamisme des communautés (dynamisme militaire durant la phase guerrière de la Reconquête puis dynamisme économique), exprimer des revendications constitue toujours une certaine prise de risque; le plus évident est la pression exercée par l'adversaire (le seigneur) si l'affaire est portée à arbitrage ou jugement, pouvant aller jusqu'aux menaces de violence physique et parfois à son emploi - quoiqu'il faille rester prudent car ce sont les seules déclarations des intéressés qui attestent ce risque : plusieurs témoins dans des passages non publiés de la source IO3 insistent sur les menaces du commandeur santiaguiste en cas de plainte. Quand le litige est contentieux, le risque financier n'est pas négligeable non plus, non seulement en cas de jugement contraire mais aussi par l'engagement des frais de procédure (cf. condamnation dans la source 99 à Iıo livres de droit de greffe et allusion dans la source IO2 à "as custas Eas despesas»), lourds pour des budgets municipaux fragiles, d'autant plus que les seigneurs, aux reins plus solides, s'entendent à faire trainer les procès (source IO2). Un dernier risque est d'ordre politique : l'exercice de la juridiction suprême par la monarchie constitue une garantie pour les communautés mais introduit le loup dans la bergerie, dans la mesure où les monarques tranchent entre les divers intérêts dans le sens d'une uniformisation, invoquant la "coutume du royaume " (source 99) aux dépens de la coutume locale avancée par la communauté plaignante (et la capacité reconnue au monarque de "réformer" les coutumes est une arme de la centralisation).

Au-delà du discours unanimiste, on peut supposer des intérêts "catégoriels " dans le contenu même des revendications ; on sait que les "chevaliers vilains" puis les élites de «bonshommes» qui leur succèdent pèsent de tout leur poids dans la concession des chartes de franchises - en fait, dans la structuration même des groupes de colons en tant que communautés - et dans la présentation des 
" chapitres» de revendications aux Cortes. Cependant, il n'est pas facile de voir dans ces seuls documents une orientation oligarchique; certes, les saisies évoquées dans les sources IO2 et IO3 touchent plus durement les possédants que les misérables mais les seuls actes de la pratique administrative et politique interne qui nous restent (notamment les délibérations communales) montrent que les villages (Messejana, Padrões) et les petites villes (Loulé, Avis), contrairement aux rares " grandes " villes, maintiennent un sens aigu de l'intérêt du plus grand nombre, peut-être à cause de leur archaïsme économique (cadeaux de vin de la source 99) mais surtout parce que l'instrumentalisation du pouvoir (au profit d'une oligarchie économique ou morale puis «savante») tarde à s'y opérer ${ }^{9}$. De plus, la solidarité communautaire est tellement indispensable pour résister à l'"offensive seigneuriale" que l'oligarchie municipale - en train de monopoliser et instrumentaliser le pouvoir - se doit d'agir contre tout empiètement seigneurial, fût-il mineur et aux dépens de citoyens peu importants, car elle défend en même temps ses prérogatives; on le voit bien dans la source IO2, l'action menée par le concelho d'Avis contre son seigneur implique une solidarité de toute la communauté.

En définitive, les malversations (plus ou moins claires d'un point de vue juridique) dont se rendent coupables les administrateurs seigneuriaux ne mettent pas en péril la survie même des sujets mais seulement les revenus et les prérogatives de tout ou partie de la communauté : l'enjeu essentiel de ces revendications est bien le contrôle et l'exercice de certains pouvoirs ; même si l'exercice quasiment mécanique des solidarités est bien garanti par le système municipal, ce sont donc les élites qui bénéficient plus ou moins directement des actions. Si l'on observe maintenant non plus les intérêts sociaux mais les principes qui les expriment, ce sont des conceptions du droit qui s'opposent, tout autant ou même plus que des intérêts vénaux; dans le partage politique toujours boiteux entre dirigeants et communautés, les sujets fondent la vérité et la justice (en tant que concept) sur la coutume tandis que les seigneurs - le roi en tête, à la fois en tant que seigneur " direct » et en tant que souverain - fondent leur administration sur la loi ; mais le principal lieu de rencontre de ces conceptions opposées (et donc lieu d'évolution du droit) est la juridiction contentieuse, où agissent de plus en plus des légistes, porteurs d'un droit monarchique législatif - avant même que le droit canonique puis romano-canonique ne vienne leur donner les instruments de leur combat. Au Portugal comme ailleurs - sauf l'obstacle que constitue la généralité du système municipal -, les communautés d'habitants partent vaincues d'avance dans leur inégal combat contre l'appareil administratif d'État pour le maintien d'un droit "d'initiative populaire".

9. C'est ce que j’ai observé dans la politique fiscale du gouvernement municipal de Loulé à la fin du XIVe siècle: Stéphane BoIsSELLIER, «Les dépenses d'un concelho portugais, Loulé (Algarve), à la fin du XIVe siècle à travers les délibérations du conseil municipal ", in Denis MENJoT, (éd.), La Fiscalité des villes au Moyen Âge (France méridionale, Péninsule ibérique) : 3. L'utilisation des recettes fiscales: les dépenses publiques, Privat, 200I [communication à la table ronde franco-espagnole de Chambéry de septembre 1998]. 


\section{BIBLIOGRAPHIE}

Barros, Henrique da Gama, História da administração pública em Portugal nos séculos XII a XV (2a ed. organizada por Torquato de Sousa Soares), Lisbonne, 1945-1954, II vol. [particulièrement les vol. I, III et XI].

BOISSELliER, Stéphane, Naissance d'une identité portugaise. La vie rurale entre Tage et Guadiana de l'slam à la Reconquête (Xe-XIVe siècles), Lisbonne, 1998 [maxime p. 332-45];

-, [à paraître], «Population musulmane, colonisation et encadrement municipal : une exploitation sociale de l'espace dans le Midi portugais?", in L'Organisation de l'espace rural au Portugal et dans d'autres régions occidentales (XII-XIVe siècles) : convergences et divergences des modèles. Journée d'étude en hommage à Robert Durand (Paris, 24 septembre 1999).

CAETANO, Marcelo, História do direito português. Fontes-direito público (II40-I495), Lisbonne, 1985 .

Coelho, António Borges, Comunas ou concelhos, Lisbonne, 1986.

Coelho, Maria Helena da Cruz, "Relações de domínio no Portugal concelhio de meados de Quatrocentos", Revista portuguesa de história, 25, Coimbra, 1989-1990, p. 235-289;

—, et MAGAlHĀES, Joaquim Romero, O poder concelhio das origens às Cortes constituintes. Notas de história social, Coimbra, 1986.

DurAND, Robert, Les Campagnes portugaises entre Douro et Tage aux XII et XIII siècles, Paris, coll. "Civilisation portugaise, IX", I982.

Herculano, Alexandre, História de Portugal desde o começo da monarquia até o fim do reinado de Afonso III, vol. IV, Lisbonne, I980-198I.

MARQues, José, "O concelho alentejano de Figueira e a Ordem de Avis, em I336», Revista de Faculdade de Letras-História, 5 (2a série), Porto, I988, p. 95-III;

-, "D. Afonso IV e as jurisdições senhoriais", in Actas das III jornadas luso-espanholas de história medieval, vol. I, Porto, I990, p. I527-1566 ;

—, "Os municípios portugueses dos primórdios da nacionalidade ao fim do reinado de D. Dinis. Alguns aspectos", Revista da Faculdade de letras, Io (2a serie), Porto, I993, p. 69-90;

-, "A Ordem de Santiago e o concelho de Setúbal, em I34I", in As Ordens militares em Portugal e no Sul da Europa, Lisbonne, 1997, p. 285-305.

Moreno, Humberto Baquero, Os municípios portugueses nos séculos XIII a XVI. Estudos de história, Lisbonne, 1986.

NogueIRA, Bernardo de Sé, "A constituição do senhores fronteiriço de Marvão, Portalegre e Arronches, em I27I. Antecedantes regionais e significado político ", A cidade, 6 (nova série), Portalegre, I991, p. 19-45.

Nogueira, José Artur Anes Duarte, Sociedade e direito em Portugal na Idade Média. Dos primórdios ao século da Universidade (contribuição para o seu estudo), Lisbonne, 1994.

ReIS, António Matos, Origens dos municípios portugueses (I055-I223), Lisbonne, coll. : "Horizonte histórico " 36, I991.

Silva, Nuno J. Espinosa Gomes da, História do direito português. Fontes de direito, Lisbonne, I991.

SousA, Armindo de, As Cortes medievais portuguesas (1385-1490), Porto, I990, 2 vol.

SOUSA, Bernardo Vasconcelos e, "Protestos anti-senhoriais em Bragança e Benavente no final do séc. XIV ", Revista Portuguesa de história, 31/2, Coimbra, p. 167-I89.

VIEGAS, Valentino, "Aspectos da vida quotidiana em Almodôvar, Castro Verde e Padrōes no tempo da Inquirição de 1375-1376", in Ordens militares. Guerra, religião, poder e cultura. Actas do III encontro sobre Ordens Militares (Palmela, 22-25 janvier 1998), Lisbonne, I999, vol. I, p. 20I-207. 


\section{7. \\ 28 janvier 1275 \\ Composition entre Maria Martins et l'Ordre d'Avis}

Composition amiable - le roi Afonso III servant d'arbitre - entre Maria Martins et l'Ordre militaire d'Avis au sujet d'une propriété foncière à Benavente, accordant l'usufruit viager du bien à la plaignante.

Sources : A: Arquivo Nacional da Torre do Tombo, Ordem de Avis, doc. 85 (original).

B : Arquivo Nacional da Torre do Tombo, Ordem de Avis, doc. 229 ( publica forma " notariale [I4 novembre I302] de la confirmation par l'Ordre [I2 février I275] de A).

\section{Traduction}

A LFONSUS DEJ GRATIA rex Portugalie et Algarbij universis presentem cartam inspectueritis notum facio quod cum contenda esset per ante me inter mariam martinj quondam uxorem Arnati parte et magistrum et Conuentum de Auis per suum procuratorem sufficientem ex altera. super eo quod ipsa maria martinj dicebat quod dictus magister et Conuentus fecerant sibi forciam super quadam hereditate que est in termino de Benauente in loco qui dicitur Traiouti deytando inde suos homines. Ad ultimum post multas rationes ab utraque parte propositas ad talem compositionem deuenerunt videlicet quod dicta maria martinj habeat teneat et possideat libere et inpace et quiete ipsam hereditatem et sine inquietatione predicti ordinis toto tempore uite sue et post mortem ipsius marie martinj ipsa hereditas debeat remanere eidem ordinj insaluo et inpace cum toto suo melioramento et dicta maria martinj debeat ad mortem suam dare eidem ordinj ducentas libras monete ueteris portugalie nunc currentis ad ualorem. Jncujus rei testimonium do inde partibus singulas meas cartas consimiles. Dante Vlixbone xuiij. die Januarij Rege mandante per Alfonsum suerij suum
Afonso, par la grâce de Dieu roi du Portugal et d'Algarve ${ }^{1}$, à vous tous qui verrez la présente charte je fais savoir qu'il y avait conflit par devant moi entre Maria Martins, veuve de feu Arnato Raimundes, d'une part, et le maître et couvent d'Avis, [représentés] par leur procureur légal, d'autre part, au sujet de la plainte de ladite Maria Martins, selon laquelle lesdits maitre et couvent lui avaient fait tort - en jetant dehors ses hommes - au sujet d'une certaine propriété qui est dans le territoire de Benavente au lieu dit Trajouce.

Enfin, après que de nombreux arguments aient été avancés par chacune des parties, ils sont arrivés à cette composition, à savoir : que ladite Maria Martins ait, tienne et possède librement, en paix et tranquillement ladite propriété, sans aucune machination du susdit Ordre, durant tout le temps de sa vie; que, après sa mort, ladite propriété doive revenir audit Ordre sans restriction et en paix avec toutes ses améliorations; et que ladite Maria Martins doive à sa mort donner audit Ordre l'équivalent de 200 livres de la vieille monnaie du Portugal actuellement en cours.

En témoignage de quoi je donne à chaque partie une charte identique. La donnant à Lisbonne le i8 janvier, le roi l'octroyant par Afonso Soares son juge suprême. João Peres l'a écrite. Ėre I3I3.

1. Afonso III, I248-I279. 


\section{$98^{1}$. \\ I8 août I28I}

\section{Convention de la communauté maure de Colares avec son seigneur}

À la suite d'abus suivis d'une enquête, la communauté conclut une convention avec son seigneur, le roi Dinis, mettant fin à un prélèvement abusif sur des terres en concession ou en alleu mais légalisant en compensation de nouveaux droits (établis par coutume depuis la conquête de II47 ?) ; la juridiction en jeu ne semble pas contentieuse.

Source : Arquivo Nacional da Torre do Tombo, Chancelaria de D. Dinis, livre I, fol. 35.

\section{Traduction}

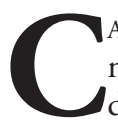

ARTA PER QUE el Rey manda aosseus mouros forros de Colares que lhy dessem o quarto

Dionisius dei gratia Rex portugaliae et

5 algarbii uniuerssis presentem cartam inspectuerint notum facio quod mei mauri forri de meo Regalengo de Colares de termino Sintrie queixauerunt se mihi dicendo quod ego leuabam medietatem fructuum

10 de illis heredamentis que ipsi habent in dicto meo Regalengo et quod non debebant aliquid inde dare mihi nec facere inde mihi istos foros. uidelicet reuoluere adubare et rreficere mea palacia de oliua et casas de Almedinis uetulis de meo castello de Sintra et adubare eyrados de Turribus et facere quedam alia quae usque modo mihi et meis antecessoribus dicti maurij fecerunt. Et ipsi mari [sic] dicebant quod pater meus fecerat eis per forciam dare medietatem de fructibus de predictis heredamentis. Et ego mandaui super hoc facere inquisitionem et inueni per inquisicionem quod predicti mauri non debent mihi dare nisi quartam partem fructuum de illis heredamentis que sunt in ipso meo regalengo que comparauerunt et habuerunt de christianis et quod non debent dare aliquid de illis heredamentis que sunt in ipso meo

30 regalengo que fuerunt de mauris ex populacione ipsius loci nisi debent facere foros supradictos. Et inueni quod pomerium meum de Colares est totum meum quiete libere et quod ipsi mauri debent eum mihi 40 custodire plantare excauare rigare tapare laborare et adubare bene tanquam si eset suum. Et ego conueni com predictis
Charte par laquelle le roi ordonne à ses maures libres ${ }^{2}$ de Colares qu'ils lui donnent le quart.

Dinis, par la grâce de Dieu roi du Portugal et d'Algarve ${ }^{3}$, à tous ceux qui verront la présente charte je fais savoir que mes maures libres de mon reguengo 4 de Colares du territoire de Sintra se sont plaints à moi en disant que je prélevais la moitié de la production des domaines qu'ils ont dans mondit reguengo et qu'ils ne devaient pas m'en donner quoi que ce soit ni m'y faire ces prestations, à savoir : amender et refaire mes bâtiments d'Oliva et les logements de la vieille citadelle de mon château de Sintra, entretenir les terrasses des tours et faire certaines autres choses que lesdits maures ont faites jusqu'alors à moi et à mes prédécesseurs ${ }^{5}$.

1. Charte transcrite dans Boissellier, I998, mais avec plusieurs fautes dues à la mauvaise qualité de la photocopie tirée du microfilm (notamment dans la lecture des abréviations en suspension, illisibles) ; lecture corrigée ici après consultation de l'" original" (c'est-à-dire du microfilm).

2. Les mouros forros (<arabe hurr) sont les Andalous vaincus (mudéjares) bénéficiant d'un statut légal (sujets de droit, quoique infériorisés par rapport aux sujets chrétiens), en raison semble-t-il de leur appartenance à une communauté maure constituée en municipe ; des communautés de ce type sont connues par leur charte municipale à partir de II70. L'effet le plus important de ce statut est la liberté de culte.

3. Roi de 1279 à I325.

4. Espaces « retenus" (par soustraction aux territoires organisés en municipes ou confiés à la juridiction d'un donataire) par les monarques et restant sous leur administration directe, par opposition aux zones municipales constituant une seigneurie indirecte. Organisés essentiellement en domaines fonciers, ils servent surtout, au sud du Mondego, à organiser le réseau des centres de pouvoir ; au sein de cette moitié méridionale, les reguenguos d'entre Tage et Guadiana "retenus" durant la colonisation - il y en a d'autres constitués plus tardivement - semblent être formés par les zones de colonisation chrétienne faible ou nulle et de population indigène importante.

5. La tournure employée permet de supposer que ces corvées ont été converties en une taxe compensatoire assise sur certains biens et plus-values ; d'après les revendications, les domaines sur lesquels pèse le croît de cens abusif ont été également inclus, tout aussi illégalement, dans l'assiette de cette taxe compensatoire. 
mauris isto modo quod de cetero dent mihi quartam partem de pane de uino de lino de leguminibus et de omnibus aliis fructibus de omnibus heredamentibus que ipsi sunt in dicto meo regalengo tam de hereditatibus quas habuerunt de christianibus quam de hereditatibus quas abuerunt ex populacione ipsius loci et quod dent mihi quartam partem de illo quo laborauerint in dicto meo pomario tam ipsi quam christiani qui ibi laborant et laborauerint et debent mihi adubare dictum meum pomerium ut superius dictum est et si illud bene non laborauerint ego possim isti auferre de meum pomerium et debent mihi facere omnes [?] supradictos et omnes arbores ipsius mei pomerii et fructus eorum et madeira et calumpnie ipsius mei pomerii remanent proadme. In cuius Rey testimonium do eis istam meam cartam. Dante ulixbone XVIII die agustii Rege mandante per suam curiam Alfonssus Martini notuit Era Ma CCCa XIX.
Et lesdits maures disaient que mon père [Afonso III] leur avait fait donner arbitrairement la moitié de la production des susdits domaines.

J'ai donc ordonné de faire une enquête sur ceci et j'ai trouvé par cette enquête que les susdits maures ne doivent me donner que le quart provenant des domaines de mondit reguengo qu'ils ont acquis ou eus de chrétiens et qu'ils ne doivent rien donner des domaines de mondit reguengo qui ont appartenu aux maures depuis le peuplement dudit lieu, à l'exception des prestations susdites. Et j'ai trouvé que mon verger de Colares m'appartient totalement en paix et sans aucune restriction et que lesdits maures doivent me le garder, planter, labourer, arroser, enclore, travailler et soigner aussi bien que s'il était à eux.

Et j'ai convenu avec les susdits maures que, à partir de maintenant : ils me donnent pour le reste le quart des grains, du vin, du lin, des légumes et de toutes autres productions de tous les domaines qui sont dans mondit reguengo, aussi bien des propriétés qu'ils ont eues de la part de chrétiens que des propriétés qu'ils possèdent depuis le peuplement dudit lieu ; et qu'ils me donnent le quart de ce qu'ils produiront dans mondit verger, aussi bien eux que les chrétiens qui y cultivent et y cultiveront ; et ils doivent s'occuper pour moi de mondit verger comme il a été dit plus haut. Et s'ils ne le travaillent pas bien, que je puisse les chasser de mondit verger; et ils doivent me faire toutes les prestations susdites; et que tous les arbres, leur produit, leur bois et les amendes [afférant aux droits d'usage] de mondit verger me reviennent à moi.

En témoignage de cette chose, je leur donne cette charte. La donnant à Lisbonne le I $8^{e}$ jour d'août, le roi l'octroyant par sa curie. Afonso Martins l'a écrite. Ère I319.

99.

\section{4 janvier I29I}

\section{Jugement du roi Dinis désavouant le commandeur de l'ordre de Santiago}

Jugement par le roi Dinis de la procédure (en instance royale) engagée à la suite d'une plainte de la communauté de Messejana contre son administrateur, un commandeur de l'Odre militaire de Santiago, au sujet d'abus dans l'administration du banvin.

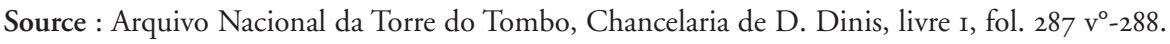




\section{Traduction}

D OM DENIS PELA GRAÇA de Deus Rey de Portugal e do algarue. A quantos esta carta vyrem faço saber que sobre contenda que era perante amim antre os joyzes e oConçelho de Mesegena per Domingos soariz seu procurador per huma procuriçom [sic] que ende eu uj da huma parte e Gonçalo eanes correya per vasco eanes seu procurador per huma procuraçom que ende eu uj da outra sobre enbargamentos do Relego que esse Conçelho dizia que lhy esse Gonçalo eanes fazia sobrel. Inprimeyramente dizia que lhys fazia embargamento por que el querrya que nem huum uizino de Mesegena nom metesse vino de fora na vila para seu beuer nem em outra maneyra emandaua lho filhar das casas e póynalhys pena de X libras e querria a leuar deles. E eu sobresto ouuydas as razóoes da huma parte e da outra e sabudo ocustume do meu Reyno julgando mandey e mando que vezinos de Messegena adugam vino de fora para seu beuer e esto seer sem enganoe sen burla e sem malicia. E sse vizinos demessegena adusserem vino de fora parte para uender aauila de Messegena em tempo do Relego dem o seu dereyto ao Senor de Messegena assy como o dam ena vila de

30 Beia. Item dizia odicto procurador que lhys fazia desaforamento odicto Gonçalo eanes por que nom querria que beuessem das [nas?] sas casas do seu vino dassa adega. e que se nom fezessem presentes do seus vezinos huuns outros nem aoutros. $\mathrm{E}$ eu sobresto ouuydas as razóoes assy dahuma parte come da outra e auhudo conçelho sobre todo julguey e julgo que os vezinos de Mesegena beuam do seu vino e que sse façam presentes huus outros ouaquem quiserem e esto seia sem engano e sem malicia. Item dizia odicto procurador do dicto conçelho que Gonçalo eanes lhys demandaua que os vezinos de Mesegena

50 iurassem sobrelos sanctos auangelos que nom beuessem outro vino em tempo do
Dom Dinis par la grâce de Dieu roi du Portugal et d'Algarve, à tous ceux qui verront cette charte je fais savoir qu'il y avait par devant moi un procès entre les juges et le concelho de Messejana - [représentés] par Domingos Soares, leur procureur au moyen d'une procuration que j'ai vue - d'une part, et Gonçalo Eanes Correia- [représenté] par Vasco Eanes, son procureur au moyen d'une procuration que j'ai vue - d'autre part, à propos du banvin, au sujet duquel le concelho disait que ledit Gonçalo Eanes lui faisait des empêchements.

Premièrement, il leur faisait dommage en exigeant qu'aucun voisin de Messejana n'introduise dans la ville de vin produit au dehors pour sa consommation ni pour autre chose et en faisant confisquer ce vin dans les maisons avec une amende de io livres qu'il voulait lever sur eux.

Moi, en tant que juge, ayant entendu les arguments de part et d'autre et connaissant la coutume de mon royaume, j'ai ordonné et ordonne que les voisins de Messejana importent du vin du dehors pour leur [seule] consommation et que ceci soit sans tromperie, fourberie ni malice ; et si les voisins de Messejana importent du vin du dehors pour vendre dans la ville durant le temps du banvin, qu'ils donnent son droit au seigneur de Messejana comme on le donne dans la ville de Beja.

Item ledit procureur disait que ledit Gonçalo Eanes leur faisait tort en interdisant qu'ils boivent dans leur maison du vin de leur cave ni qu'ils s'en fassent présent les uns les autres [entre voisins] ou à d'autres.

Moi, ayant entendu les arguments de part et d'autre et ayant pris conseil sur tout ceci, $j$ 'ai jugé et juge que les voisins de Messejana boivent de leur vin et s'en offrent les uns les autres ou à qui ils voudront, et que ceci soit sans tromperie ni malice.

Item ledit procureur disait que ledit Gonçalo Eanes leur ordonnait de jurer sur les saints évangiles de n'avoir pas bu d'autre vin [que celui qu'ils produisent eux-mêmes] durant le banvin; et quand ils ne voulaient pas jurer, ledit Gonçalo Eanes voulait faire jurer leurs hommes et que lesdits voisins de Messejana lui paient l'amende. 
Relego e se eles nom quisessem jurar querria esse Gonçalo eanes que jurassem os seus homeens e que esses vezinos de Mesegena lhy pagassem apena. E eu sobresto ouuidas as razóoes assy da huma parte come da outra iulgo que o juramento que Gonçalo eanes pidia que o nom façam os vezinos de Mesegena nem os seus homeens. Item dizia oprocurador do dicto Conçelho que Gonçalo eanes lhys querria poner mayor pena que era custume de Relego domeu Reyno. E eu sobresto ouuydas as razóes assy da huma parte come da outra e auhudo Conçelho sobre todo julgo que o senor de Mesegena ponha sobrelo Relego dessa vila tal pena qual é posta sobrelo Relego de Beia e nom mayor. $\mathrm{E}$ eu mando e outorgo que estes meus

70 joyzos se guardem e se cumpram para sempre antre os vezinos de Mesegena e odicto Gonçalo eanes e os senhores que pelo tempo forem de Mesegena e mando que lhys nom passem so pena dos meus encoutos. E condapney esse Gonçalo eanes em C libras de custas e CX libras da portaria. Entestemoyno desta cousa dey aesses joyzes e Conçelho esta carta. Dante em coymbra quatro dias de janeyro. El Rey

80 omandou per Juyaão duraãez sobrejoyz Johane andres afez Era M.a CCCa XXIXa.
Moi, ayant entendu les arguments de part et d'autre, je juge que les voisins de Messejana ni leurs hommes ne prêtent pas le serment que demandait Gonçalo Eanes.

Item le procureur dudit concelho disait que Gonçalo Eanes leur voulait imposer une taxe plus forte que selon la coutume du banvin de mon royaume.

Moi, ayant entendu les arguments de part et d'autre et ayant pris conseil sur tout [ceci], je juge que le seigneur de Messejana impose pour le banvin de cette ville la même peine qui est levée à Beja pour cela et pas plus. Et j'ordonne et octroie que mes juges observent et fassent respecter ceci pour toujours entre les voisins de Messejana et ledit Gonçalo Eanes et les seigneurs qu'il pourra y avoir à Messejana et qu'ils ne leur laissent pas outrepasser [ce jugement] sous peine de mes regalia. Et j'ai condamné ledit Gonçalo Eanes à Ioo livres de frais et Iıo livres de droit de greffe.

En témoignage de quoi j'ai donné à ces juges et au concelho cette charte. La donnant à Coimbra, le 4 janvier. Le roi l'a baillée par Juliâo Durães, juge suprême. João Andres l'a faite. Ëre de I329.

IOO.

\section{6 décembre 1292}

\section{Composition amiable entre le municipe de Santarém et l'Ordre d'Avis}

Au sujet des limites entre les municipes desdits lieux ; un nouveau (?) bornage est réalisé et les droits d'usage sont maintenus (en compascuité ?) en l'état antérieur.

Source : Arquivo Nacional da Torre do Tombo, Ordem de Avis, doc. 80.

D on Denis pela graça de Deus rey de Portugal e do Algarve. Atodos aqueles que esta carta uyrem faço assaber que sobre contenda que era per 5 ante mjm antre dom joham perez Meestre de Auis per sy e Johan martinz Comen-

\section{Traduction}

Dom Dinis, par la grâce de Dieu roi du Portugal et d'Algarve, je fais savoir à tous ceux qui verront cette charte qu'il y avait procès par devant moi entre Dom João Peres, Maître d'Avis ${ }^{1}$, pour lui-même ainsi que João Martins,

1. Milice de chevaliers constituée dans les années II70 à 
dador mayor e Lourenço Fernandiz procuradores auondossos do Conuento de Auis a estas cousas que se seguem da Huma parte.

10 Eos alcayde e aluazijs e Concello de Santarem per Vicente Anes seu procurador auondosso a estas coussas que se seguem da outra sobre termhos dantre Santarem e Auis os quaes termhos dizia o Meestre e o

15 Conuento de suso dicto que eram seus. Eoutrosy dizia o Alcayde e os Aluazijs e o Concello de Santarem que eram seus andado per ante mjm em essa demanda. Eu ouuidas muytas razoes da huma parte e

20 da outra o Meestre per sy com gram peça de ffreyres. Eos dictos procuradores do dicto Conuento. Eo alcayde e os aluazijs e peça de homeens boons e o procurador do dicto Concello de seu prazimento auee-

25 ronse em esta maneyra conuem assaber queo Concello de Santarem ouuesse huma Legua de termho por seu de Soor aalem de contra Auis. Eesta Legua começasse enas Mestas e indo a enfesto per essa Agua de

30 Soor aca em dereito do padrom peruse parte o Termho de Aurantes cono de Santarem em talmaneyra que seia huma Legua em Ancho de Soor contra Auis e o Al dessa Legua Adeante contra Auis ficou por

40 termho de Auis e por seu. Eeu doutorgamento e de consentimento das partes de suso dictas tiuj porbem demandar diuisar e demarcar essa legua e esses termhos Assy como de suso he dicto. Emandey hy Pedro

45 paaiz meu clerigo. e Roy paaiz bugallo meu uassalo. e Domingos ihanes Tabelliom de Santarem que uijse comose metiam esse marcos e diuisoes e peru e que desse en de testemunyo. Ea estas coussa forom hy pre-

50 sentes o dicto Meestre porsy e o dicto Comendador procurador do Conuento de Auis foy hy polo dicto Conuento e joham Anes procurador do Concello de Santarem foy hy polo Concello de Santarem. Eo

55 dicto Pedro paaiz e Roy paaiz cono dicto Tabelliom forom a esses logares e meterom Marcos e começarom ameter os marcos a huma Legoa em dereyto das mestas contra grand commandeur, et Lourenço Fernandes, procureurs idoines du couvent d'Avis pour les choses qui suivent, d'une part, et les alcaide et alvazis $^{2}$ et municipe de Santarém, [représentés] par Vicente Eanes, leur procureur idoine pour les choses qui suivent, d'autre part, au sujet des limites entre Santarém et Avis, dont le maître et couvent susdits, ainsi que les alcaide, alvazis et municipe de Santarém, disaient qu'elles leur appartenaient; cette plainte est [donc] venue par devant moi. Après que j'aie entendu les nombreux arguments de part et d'autre, le Maître avec de nombreux frères et lesdits procureurs dudit couvent ainsi que les alcaide, alvazis et de nombreux "bonshommes» et le procureur dudit municipe se sont accordés de leur plein gré de la manière qui suit : à savoir que le municipe de Santarém possède une lieue de territoire au-delà de [la rivière] Sor vers Avis ; que cette lieue commence depuis les Mestas en remontant par cette rivière de Sor en direction de la borne qui sépare le territoire d'Abrantes de celui de Santarém, de telle façon qu'il y ait une lieue de large depuis [la rivière] Sor vers Avis ; que le reste de cette lieue en direction d'Avis appartienne au territoire d'Avis. Et moi, avec le consentement et le mandat des parties susdites, j'ai tenu pour bon de faire diviser et démarquer cette lieue et ces limites comme il est dit cidessus. Et j'ai envoyé là Pedro Pais, mon clerc, et Ruy Pais Bugalho, mon vassal, ainsi que Domingos Eanes, notaire de Santarém, pour qu'il voie comment et où seraient mises ces marques et divisions et qu'il en donne témoignage. Furent présents à cette sentence ledit Maître pour lui-même, ledit commandeur, procureur dudit couvent, [qui] était là pour ledit

Évora pour la défense de la ville puis transformée en Ordre (règle cistercienne) par affiliation à l'Ordre castillan antérieur de Calatrava ; recevant la garde de fortifications exposées d'Alentejo puis la juridiction de sites fortifiés d'Estremadura, du Ribatejo et d'Alentejo, l'Ordre implante son siège sur le site (devenu rapidement éponyme) d'Avis en I2II et contribue à la colonisation du haut Alentejo, exerçant une juridiction quasi souveraine (mais toujours en rapport étroit avec les monarques) dans la zone.

2. L'alcaide (< arabe qäid) est un représentant du roi (ou toute autre autorité de tutelle) au sein des municipes; comme sa principale attribution primitive est la conduite des troupes, il réside ordinairement dans la citadelle (alcáçova) du chef-lieu municipal et exerce une juridiction d'étendue variable mais généralement importante. Les alvazis (singulier alvazil< arabe wazir=gouverneur), nommés aussi judices/juizes ou encore alcaldes (< arabe qadi), sont les juges municipaux, exerçant la plus haute juridiction civile et judiciaire et représentant la communauté locale auprès des autres instances. 
Auis. e poserom Marcos em tal logar 60 Conuem assaber [... localisation des bornes]. Eper estes Marcos nom tolho seu dereyto das dizemas a Ordim de suso dicta de contra soor Assy como Ante hussauam. Eoutrosy deuem de pacer e de talhar de suum em esses termhos Assy come vezinos tam Bem eno termho que fica a Ordim de Auis come aoque fica Ao Concello de Santarem. e as partes pedirom Amjm por mercee que esto quelho desse em Juyzo

70 que ualesse para todo senpre. Eeu de prazimento das partes de suso dictas julgando mandey e mando que Assy uala para todo senpre todas estas coussas e cadahuma delas. Assy como he de suso dicto e deuissado e demarcado e poresta coussa seer mays firme e mays stauil fezerom duas cartas seeladas dos seelos do Meestre e do Conuento de auis e do Seelo do Concello de santarem. e do meu que see nomeyogoo

80 [?]. Dante em Santarem vijnteseix dias de Dezembro. El rey omandou com sa corte. Duran perez affez Era de Mil e Trezentos e Trijnta anos. couvent, et João Eanes, procureur du municipe de Santarém, [qui] était là pour le municipe de Santarém. Et lesdits Pedro Pais et Ruy Pais avec ledit notaire allèrent en ces lieux, mirent les marques et ils commencèrent à les mettre à une lieue depuis les Mestas vers Avis; et ils ont posé les bornes [énumération du bornage].

En deçà de ces bornes vers [la rivière] Sor, je n'enlève pas au susdit Ordre son droit aux dîmes, comme ils en usaient auparavant ; de même, ils doivent paître et couper [du bois] dans leurs limites respectives, en tant que voisins, aussi bien dans le territoire qui reste à l'Ordre d'Avis que dans le territoire revenant au municipe de Santarém. Et les parties m’ont demandé en grâce que ce que je leur donne en jugement soit valable à perpétuité; avec l'accord des parties susdites, $j$ 'ai donc ordonné et ordonne que toutes ces choses et chacune d'elles vaillent perpétuellement dans la modalité qui est dite plus haut et comme cela a été démarqué et divisé. Pour que cette chose soit plus ferme et stable, ont été faites deux chartes scellées des sceaux du Maître et couvent d'Avis et du sceau du municipe de Santarém ainsi que du mien. La donnant à Santarém, le 26 décembre. Le roi l'a mandée avec sa cour. Duran Perez l'a faite. Ère de I330.

IOI.

\section{I8 novembre 1299}

\section{Le municipe de Portalegre demande confirmation de ses coutumes ${ }^{1}$}

Après son aliénation dans l'apanage de l'infant Afonso puis sa réintégration sous seigneurie monarchique directe, le municipe royal de Portalegre demande confirmation de ses coutumes.

Source : Arquivo Nacional da Torre do Tombo, Chancelaria de D. Dinis, livre 3, fol. 8-8 v

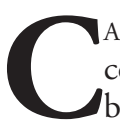

ARTA PER QUE ELREY outorga ao concelho de portalegre todo seu boom foro que sempre ouuerom

Dom Denjs pela graca de deus Rey deportugal e do algarue auos Concelho de portalegre saude enuiastes pedir que Eu uos outorgasse ouosso foro e os uossos custumes e acarta de benfeitoria que uos elRey dom Affonsso meu padre deu. Eu querendouos fazer graça e merce outorgouos o uosso foro. e acarta da benfeitoria que uos el Rey dom Affomso meu padre deu e outrossi uos outorgo os uossos husos e os uossos custumes boons assi comoos ataaqui ouuestes.

\section{Traduction}

Charte par laquelle le roi octroie au concelho de Portalegre tout son bon droit qu'il a toujours eu

Dom Dinis, par la grâce de Dieu roi du Portugal et d'Algarve, à vous concelho de Porta-

1. Publié avec quelques erreurs et lacunes de transcription dans História florestal, aquícola e cinegética. Colectânea de documentos existentes no Arquivo Nacional da Torre do Tombo - Chancelarias reais -, vol. I (I208-I483 [lire I438]) (dir. C. M. L. Baeta Neves), Lisbonne, 1980, p. 43-44; notons que ce volume regorge de revendications de communautés paysannes portant sur les droits d'usage, lieu de rencontre capital pour la conception et l'exercice du pouvoir (opposant aussi bien les communautés entre elles que les communautés contre leur seigneur et même, à partir du milieu du XIVe siècle, les communautés contre certains de leurs membres privilégiés). 
Outrossi do que menuiastes dizer e pedir que eu que que [sic] uos nom desse a Iffante nem a Ricomem nem a rica dona nem aoutro homem nem huum. senom que senpre fossedes meus e do meu filho primeiro herdeiro que despos mjm Reinar e daquelles Reys que despos mjm rreynarem. Eu querendouos hj fazer graça e merce outorgouolo. E mando e deffendo que uos nom seiades dinffante nem de

25 Ricomem nem de Rica dona. nem doutro homem nem huum. se nom meus e de meu filho primeiro herdeiro que despois mjm Reynar e daquelles Reys que despos mjm ueerem.

Outrossi do que menuiastes pedir que amata dalcugul e arribeira de Nisa que uos ffilhara dom Affonso meu Jrmaão e poyna hj deffesa. Eque leuaua de uos muyta coomha per esta razom e que eu que uos

35 outorgasse que husassedes dela. Eu querendo uos fazer graça e mercee. mandouos que husedes dela e que nom leuem de uos outra coomha.

Outrossi do que menuiastes dizer que

40 os uossos juizes prendiam e julgauam e matauam aquelles que mereciam morte por que. Eque meu yrmaão dom Afonso tolheu este poder aos juizes e que o pos no seu Almuxarife. E eu querendo uos fazer

45 graça e mercee. tenho por bem que o meu almuxarife que prenda e que aduga perante os juzes [sic] e os juizes julguem assi como acharem que he de dereito. Outrossi do que menuiastes pedir que o meu alcayde

50 que teuer o Castello de portalegre que nom ouuesse poderio sobre uos. Eu querendouos fazer graça e mercee tenhoo por bem e mando e deffendo que o meu Alcayde que teuer esse Castello que nom

55 aia nem huum poderio sobreuos se nom solamente en guardax esse castello. Outrossi do que menuiastes dizer que metiades uossos montarases pera guardar uossas vinas e coutadas e ortas e que poyn-

60 hades nos degredos sobresto que leuassem daquelles que hj achassem fazer dano. e legre, salut. Vous avez fait demander que je vous octroie votre droit et vos coutumes et la charte de bienfait que le roi Dom Afonso [III] mon père vous a donnée. Moi, voulant vous faire grâce et merci, je vous confirme votre statut et la charte de bienfait que le roi Dom Afonso mon père vous a donnée ${ }^{2}$ et je vous confirme aussi vos bons usages et vos bonnes coutumes comme vous les avez eus jusqu'alors.

De même, vous m'avez envoyé dire et demandé que je ne vous donne pas à quelque infant, riche homme, riche dame ${ }^{3}$ ni à aucun autre homme et que vous soyez toujours miens et à mon fils premier né héritier régnant après moi et aux autres rois qui régneront après moi. Moi, voulant vous faire grâce et merci, je vous octroie et ordonne et défend [... reprend la formule de la demande ad notam].

De même, vous m'avez fait dire que Dom Afonso mon frère vous a pris la forêt d'Alcugul et la rivière de Nisa et les a mises en défens et qu'il levait sur vous à cause de ceci de nombreuses amendes; et [vous m'avez fait demander] que je vous octroie l'usage de ces choses. Moi, voulant vous faire grâce et merci, je vous accorde d'en user et qu'on ne lève plus d'autre amende sur vous.

De même, vous m'avez fait dire que vos juges arrêtent, jugent et exécutent ceux qui méritent la mort et que mon frère Dom Afonso a pris ce pouvoir aux juges et l'a donné à son almoxarife 4 . Et moi, voulant vous faire grâce et

2. On notera qu'on ne conserve aucune charte municipale pour le site de Portalegre même, quoiqu'il soit devenu dans la seconde moitié du XIII ${ }^{e}$ siècle une des principales villes méridionales et soit d'ailleurs désigné comme concilium à part entière dès 1253 (après avoir été un simple village inclus dans le vaste territoire dépendant de Marvão, site ayant reçu une charte propre); la tournure employée ("forum et costume») ne permet pas d'affirmer que Portalegre a reçu son statut par une véritable carta et le seul document auquel il soit fait allusion est une carta de benefactoria (en portugais), c'est-à-dire un acte plus partiel que la carta fori proprement dite : il semble donc que soit en vigueur dès le milieu du XIII ${ }^{e}$ siècle l'usage diplomatique (pratiqué par le roi et l'Ordre militaire d'Avis, notamment) de conférer le statut municipal (ou, plus largement, organique) sans diplôme parfaitement ad hoc. Cette pratique permet au seigneur d'atténuer, pour ces nouveaux municipes, la réciprocité et l'égalité entre contractants qu'implique la nature contractuelle des chartes municipales. Sur le contexte : NogueIRA, I99I.

3. Infant est le titre traditionnel porté par les enfants royaux ; rico homem (emploi très rare en latin) = "riche homme " (avec son féminin, beaucoup plus rare dans la pratique) est le titre porté par les gouverneurs des circonscriptions civiles anciennes (les terras, n'existant qu'au nord du Mondego), titre qui finit par désigner, dans la seconde moitié du XIII ${ }^{e}$ siècle, la plus haute catégorie de la noblesse.

4. Agent fiscal percepteur et gestionnaire (mise aux enchères, affermage) des revenus du seigneur et pouvant 
que estas coomhas que senpre as uos leuades e que o almuxarife de dom Afonso os prendiam que lhy dessem o terço das coomhas e que per força lhas auiades adar. Eu querendo uos hj fazer graça e mercee tenho por bem que as aiades e que o meu almuxerife nom uos faça hj força sobrelas. En testemunyo desto dou uos esta mha

70 carta seelada do meu seelo do chunbo. Dante en Portalegre XVIIJ $^{\circ}$ dias de Nouembro. ElRey o mandou per sa corte. Lourenço Stevez da guarda afez. era M. CCC XXXVIJ. anos merci, je tiens pour bien que [ce soit] mon almoxarife qui arrête et conduise devant les juges et que ceux-ci jugent comme ils trouveront qu'il est de droit.

De même, vous m'avez fait demander que mon alcaide tenant le château de Portalegre n'ait pas juridiction sur vous. Moi, voulant vous faire grâce et merci, je tiens pour bien, ordonne et défends que mon alcaide tenant ce château n'ait sur vous d'autre juridiction que celle concernant la garde de ce château.

De même, vous m'avez fait dire que vous mettiez vos gardes forestiers pour garder vos vignes, défens et jardins, que vous fixiez par décrets ce qu'ils doivent prendre de ceux qu'ils trouvent y commettant des dégâts - amendes que vous avez toujours levées vous-mêmes - et que l'almoxarife de Dom Afonso se faisait donner le tiers de ces amendes de telle sorte que, contre le droit, vous ayez à les lui donner. Moi, voulant vous faire grâce et merci, je tiens pour bien que vous les ayez et que mon almoxarife ne vous force pas à ce sujet.

En témoignage de quoi, je vous donne cette charte scellée de mon sceau de plomb. La donnant à Portalegre le is novembre, le roi l'a octroyé par sa Cour. Lourenço Esteves de Guarda l'a faite. Ère de 1337.

exercer à ce titre la justice fiscale, dont le nom (< arabe mushrif) se répand au Portugal à la fin du XII siècle.

IO2.

juillet 1309

Jugement royal entre le municipe d'Avis et son seigneur

(en transcription dans le jugement royal du 4 novembre I350, lui-même en copie conforme $\mathrm{du}$ ?) [document tronqué au début ; mauvais état de conservation].

Au sujet d'une saisie de biens devant garantir la paiement de l'amende punissant l'infraction du délai légal de viduité ; un premier accord (amiable ?) favorable au seigneur, l'Ordre militaire d'Avis, a été interjeté par les plaignants puis successivement cassé et confirmé par plusieurs instances.

Source : Arquivo Nacional da Torre do Tombo, Ordem de Avis, maço 4, doc. 459.

\section{Traduction}

[sous réserve des lacunes dans la transcription]

... rom atal Auença sobresto que o dicto mestre mandara penhorar como he costume daujs [...] e vynte e trynta e çjnquo [sic] Anos e majs Asy que a memorya dos 5 homens nom he ocontrairo que nehuuns
... ils arrivèrent à un accord au sujet de ce que le Maître avait fait saisir selon la coutume d'Avis... [Mais selon cette coutume] datant de 20,30 et 50 ans et plus - de telle sorte que la mémoire des hommes ne peut la contredire - 
vyzinhos dauys nem doutrem seer penhorados sem sendo ante chamados e ouujdos e as deujdas julgadas o qual costume foy alegado e confjrmado por mjm Edizia odicto conçelho o mestre em omes de julho que foy da Era de quarenta e sete anos que foy ante desta Era que ora anda mandaram [sic] tomar e penhorar por Joham seu homem por sa força beens moujs quantos lhy nas casas achaua agram parte dos vyzinhos do dicto logo Conuem asaber aauiuyas do dicto logo que casaram ante do Anno dizendo que [illisible] auja de leuar dellas sete mareuedjis de cada hua sem sendo ante chamadas e ouujdas como por direito e pollo costume conuem asaber

[liste des veufs et veuves avec énumération des biens saisis à chacun(e) en gage]

nom estando presente aquelles aque asy tomaram os dictos penhores amoor parte delles Jndo em esta parte contra a Auença e sentença de suso Alegada aqual penhora diziam que o dicto mestre mandara fazer dizia odicto Conçelho que era em seu pre jujzo por que os reus vyzinhos nom Eram chamados nem ouujdos nem as diujdas julgadas como seu custume e de se fazer estando os dictos vjzinhos em pose dos dictos penhores que lhis asy odicto

35 mestre mandou filhar no tempo do esbulho Eque outro si leuarom os dictos penhores para oconuento do dicto logo daujs $\mathrm{E}$ os tinham hy por seu mandado do dicto mestre $\mathrm{E}$ pedirom que o dicto conçelho pello dicto seu procurador contra odicto mestre que se gardase a e semanteuese a dicta auença e sentença suso Alegada e que o dicto mestre lhjs nom fose contra ella em parte nem em todo Eque outro ssi o dicto conçelho e vjzinhos fosem Risstjtuidos de todos aquelles beens moujs que lhe asy o dicto mestre mandara filhar em pre jujzo do dicto conçelho Eque se contra ello entendese auer alguum dereito que o demandase por hu deuja e como deuja segundo majs compridamente Era contjudo em pitjçom ello da outra parte aucun voisin d'Avis ni d'ailleurs ne doit être saisi sans être auparavant cité et entendu et ses dettes jugées; cette coutume a été alléguée et confirmée par moi. Ledit municipe disait que le Maître, durant le mois de juillet I309 avant la présente année, avait fait prendre et saisir de force par João, son homme, tous les biens meubles qu'il trouvait dans les maisons à une grande partie des voisins dudit lieu (à savoir les veuves dudit lieu s'étant remariées avant une année révolue), en prétextant qu'il avait le droit de prélever 7 maravédis de chacune d'elles sans qu'elles ne soient auparavant citées et entendues, selon le droit et la coutume. À savoir ...

[liste des veufs et veuves avec énumération des biens saisis à chacun(e) en gage]

alors que n'étaient pas présents ceux à qui l'on saisissait ainsi ledits gages.

La plus grande partie d'entre eux se déclarèrent contre l'accord et sentence alléguée cidessus; ils disaient que la saisie ordonnée par le Maître était en leur préjudice parce que les voisins accusés n'étaient pas cités ni entendus ni leurs dettes jugées comme il est dans leur coutume de faire quand les voisins sont en possession de gages. Ledit Maître avait fait saisir au moment de la moisson et ils avaient emporté lesdits gages au couvent [de l'Ordre] dudit lieu d'Avis et ils les gardaient là sur l'ordre dudit Maître. Ils avaient alors demandé : que ledit municipe, à travers sondit procureur, défende et maintienne contre le Maître ledit accord et sentence ci-dessus allégué ; que ledit Maître n’aille pas contre tout ou partie de la sentence; que soient restitués auxdits municipe et voisins tous les biens meubles que ledit Maître leur avait ainsi fait prendre en préjudice du municipe; que, s'il pensait avoir quelque droit contre ceci, il le fasse valoir en tel lieu et en telle manière comme cela était [devait être ?] exposé plus précisément dans une pétition.

De la part dudit Maître des arguments furent donnés par écrit par devant ledit Infant, par lesquels il disait ne pas être tenu de répondre, disant que ledit municipe avait porté plainte contre lui dans cette même cause par devant Gonçalo Eanes, mon corregedor ${ }^{1}$ en entre Tage et Guadiana ; et pour cela même,

1. Titre (se généralisant au cours du XIVe siècle aux dépens 
do dicto mestre foram dadas humas Razoens em escrito per dante o dicto

Jnfante em que dizia que nom era tihudo a Responder dizendo odicto mestre que o dicto conçelho posera demanda contra ell per dante Gonçalo anes Coregedor por mjm entre tejo e odiana sobre esta messma cousa e por este mesmo ljs [...] ello por que ora demandauam per dante odicto Jfante e foy tanto por ofecto com odicto conçelho por seus procuradores que fora constetado ofecto da sua parte por negaçom [illisible] nom sabja nemtjnha dados arros da parte do dicto conçelho Estando asy odicto fecto que odicto conçelho fora Reuel e a asua Reuelja que o dicto coregedor o asolvera da contestaçom e da sa sentença do Jujzo. E dizia que pojs ofecto era como dicto he que el nom Era tjudo de Responder ataa que o dicto conçelho nom pagase as custas Eas despesas que ell fizera ata que fose dada asentença contra o dicto conçelho $\mathrm{E} o$

75 dicto Jnffante por sentença mandou ao dicto mestre nom embragando noque da sua parte Era dicto que const[..] ase adicta petiçom e Julgou que adicta pitiçom tragia direito e daparte do dicto mestre foj logo contestada adicta pitiçom della por confjsom e della por negaçom E odicto Jnfante julgou que com testaua quanto auondaua e mandou ao procurador do dicto conçelho que ueese com arros oqual ueeo com elles e foram Julgados por pertenentes Emandou filhar por elles aproua Estando asy odicto fecto comyndose as dictas Enquerj̧̧oees pollos dictos arros o dicto Jnfante mandou o proceso do dicto fecto agonçalleanes meu coregedor que ujse o dicto fecto ante as dictas partes e fezese oque fose direito Eo dicto Coregedor visto oproçeso $\mathrm{E}$ as enquerj̧̧oees que sobresto foram filhadas Julgou que odicto concelho proua oque se obrigara aprouar e mandou ao procurador do dicto mestre que ueese com Razoeens a ebragar adefjnjtiua seos avjam oqual veeo com ellas Julgou que as dictas Razoens nomtragiam direito a que je les [déboute ?] parce qu’ils portaient plainte alors par devant ledit Infant. Et il a tellement esté avec ledit municipe (à travers ses procureurs) qu'il a considéré la cause comme étant en négation, surtout qu'il n'avait pas et ne connaissait pas les arrhes légalement dues de la part dudit municipe; la cause en était à tel point que le municipe avait été tenu pour contumace et, à cause de cette contumace, ledit corregedor avait absout [le Maître] de la contestation de la sentence [renvoyant] en jugement. Il disait que, la cause étant à ce point, il n'avait pas à en répondre tant que ledit municipe ne paierait pas les frais engagés par lui [le Maître] jusqu'à l'obtention de la sentence contre ledit municipe.

Et ledit Infant, par arbitrage, ordonna au Maître (nonobstant ce qui était dit de sa part) de considérer ladite pétition et il jugea que ladite pétition était légalement recevable. Le Maître contesta aussitôt ladite pétition, aussi bien en confession qu'en négation ; ledit Infant jugea qu'il contestait de manière suffisante et ordonna au procureur dudit municipe de venir avec des arrhes; celui-ci vint avec elles et elles furent estimées convenables et [l'Infant] fit établir la preuve sur elles. La cause en étant à ce point et lesdites enquêtes ayant été ordonnées grâce auxdites arrhes, ledit Infant renvoya la procédure de ladite cause à Gonçalo Eanes, mon corregedor, pour qu'il examine ladite cause devant lesdites parties et qu'il fasse ce qui est de droit.

Et ledit corregedor, ayant vu le procès et les enquêtes réalisées à son sujet, décida que ledit municipe devait prouver ce qưil s'était engagé à prouver ; il ordonna au procureur dudit Maître de venir comparaître avec des arguments valables (s'il en avait) pour contredire la [sentence] définitive et celui-ci vint avec eux ; mais [le corregedor] jugea que ces arguments n’avaient pas la force légale à contredire la sentence définitive et il établit aussitôt cette sentence, selon laquelle le Maître devait rendre auxdits voisins d'Avis tout ce qu'il leur avait fait confisquer (dans la mesure où cela était prouvé

de meirinho) désignant les représentants judiciaires du roi, d'abord extraordinaires puis permanents dans une zone donnée (comarca), exerçant la justice administrative et jugeant en appel. 
100

enbragar a defjnjtjua Emandou logo adefjnitiua e Jolgou que o dicto mestre emtregare aos dictos vjzjnhos daujs todo aquello que prouado Era polla em quirjçom que lhy odicto mestre mandara fjlhar do qual

105 feçto [sic] odicto mestre peramjm agrauou Eos meus sobre Jujzes do cjujl visto odicto agrauo Julgaram que odicto coregedor mal Julgara e coregendo seu Jujzo julgaram que se garde e mantenha a dicta auença e sen-

110 tença suso alegada Eque o dicto mestre nom fose contra ella em todo nem em parte Eoutro ssi que odicto conçelho e ujzjnhos ffossem Restjtujdos e entreges detodollos beens moujys que lhys asy odicto

115 mestre mandou fjlhar em pre Jujzo do dicto conçelho $\mathrm{E}$ que se entendese contra elles auer alguum direito que os de mandase por u deuja como djuja da qual ssenteça odicto mestre peramjm agrauou e fez

120 perante mjm vyinr odicto fecto [illisible] mjnha carta de graça por que odicto mestre me mandou dizer que fora agrauado no dicto fecto demajscom agrauos que per dante mjm mostrou. Eu

125 visto odicto fecto com os domeu conselho e a Auença que o dicto conçelho fezera com odicto mestre per dante mjm por que o conçelho podia pidjr que o dicto mestre fose constranjudo ateuella e gardalla e visto

130 em como por o dicto mestre foy confisado que mandara penhorar as vjujas que casaram antedo anno por esa Razom contjuda nadicta pitjçom como quer que porRega direito sem diujda se oconçelho

135 podja pjdjr que os penhores que fossem entreges aquelles aque foram fjlhados pero por que pella uerdade do fecto pareçe que o dicto mestre nom deua mandar fjlhar os dictos penhores sem sendo ante Julgados e

140 [.] conhados que deujam seus penhorados Julgey que

\section{[jugement royal]}

por que uos mando que ffaçades comprir e aguardar o dicto meu Jujzo e dos 145 meus sobre Jujzes do çjuel como por mjm he mandado unde al nom façades dada em par l'enquête). Le Maître appela alors de cette sentence auprès de moi.

Et mes juges suprêmes du civil, ayant examiné ledit appel, jugèrent que ledit corregedor avait mal jugé et, corrigeant son jugement, ordonnèrent : que ledit accord et sentence cidessus allégué soit gardé et maintenu et que ledit Maître ne le contrarie pas, en tout ni en partie; que soient rendus auxdits municipe et voisins tous les biens meubles que ledit Maître leur avait fait confisquer en préjudice dudit municipe; que le Maittre, s'il entendait avoir quelque droit contre eux, les fasse valoir où et comme il convient. Ledit Maître appela de cette sentence par devant moi, fit venir par devant moi ladite cause et, [se prévalant] de ma charte de grâce, me fit dire qu'il avait été lésé dans ladite cause (outre d'autres plaintes qu'il produisit devant moi).

J'ai alors examiné, avec les membres de mon Conseil, ladite cause et l'accord conclu par ledit municipe avec ledit Maitre par devant moi, selon lequel le municipe pouvait demander que ledit Maitre soit contraint de le respecter; attendu, également, que ledit Maître a reconnu avoir fait saisir les veuves remariées avant un an, pour la raison exposée dans ladite pétition, alors que le municipe a le droit (sans dommages et intérêts) d'exiger la restitution des gages; comme il semble également, d'après le procès, que le Maître n'ait pas de droit à faire saisir lesdits gages avant jugement: j’ai jugé [jugement royal]

en raison de quoi je vous ordonne de faire exécuter et respecter mondit jugement et celui de mes juges suprêmes du civil comme je l'ai baillé ; dans le cas où vous ne le feriez pas... ${ }^{2}$ Donnée à Torres Vedras le 4 novembre. Le roi l'a octroyé par ceux de son Conseil. Afonso Eanes d'Évora l'a faite. Ère de 1388.

Cette charte ainsi montrée, ledit seigneur Maître dit au juge de lui en faire donner une transcription en copie conforme ; et ledit juge l'a fait donner.

Témoins : Vasco Eanes, Tiago Del Rey,

2. Traduction (littérale) abrégée, en portugais, de la formule diplomatique latine de contrainte des agents d'exécution. 
torres vedras quatro dias de nouembro $\mathrm{El}$ Rey omandou pellos do conselho afomso anes deuora a fez Era de mjl e trezentos e outenta e oyto Anos A qual carta asy mostrada o dicto ssenhor mestre dise ao dicto Jujz que lho mandase dar otrelado della em prolyca forma e odicto jujz tha mandou por dar [illisible] testemunhos

155 vasco anes tiago delRey [?] Joham perez afomso anes aluaro monteiro e lourenço pirez e afomso euam homem delRey gonçalo ffernandez Eoutros mojto homens boons $\mathrm{Eu}$ lourenço gonçaluez tabaljom DelRey em aujs que por mandado e outorgamento do dicto Jujz este trellado desta carta escreuj e meu sjnal fjz que tal [seing notarial] he pago vynte Reais
João Peres, Afonso Eanes, Alvaro Monteiro, Lourenço Peres, Afonso Evam homme du roi, Gonçalo Fernandes et de nombreux "bonshommes ". Moi, Lourenço Gonçalves, notaire royal à Avis, sur l'ordre et octroi dudit juge, j'ai écrit la copie de cette charte et j'ai apposé mon seing qui est ainsi [seing notarial] payé 20 reis.

IO3.

Io février 1376

\section{Déposition contre un commandeur de l'Ordre militaire de Santiago}

Au cours d'une enquête d'administration patrimoniale diligentée par le roi Fernando I, déposition, parmi beaucoup d'autres, de la veuve d'un tenancier royal contre les malversations (notamment des saisies illégales) dont s'est rendu coupable un commandeur de l'Ordre militaire de Santiago dans le village (sous seigneurie dudit Ordre) de Padrões.

Source : Arquivo Nacional da Torre do Tombo, "Leitura nova », Direitos reais, livre I, fol. I56-163 (éd. Francisco C. Soares VICTOR, "Inquiriçôes no século XIV. Almodôvar e Padrōes ", Arquivo de Beja, I, 1944, p. 15-16, et 4, 1947, p. 157-158).

E MQUIRIÇOM QUE FOY tirada em a villa de beja em rrazom dos beens que el-Rey ha em almodouuar do campo dourique - Diligencia do Juiz

Porque foy dito a vaasquo perez por elRey em Beja que o dito Señor Rey avia beens no dito logo de almodouuar e que nom eram rreparados segundo compra e por que outrossy ell nom avia enformaçorn certa em rrazom dos ditos beens quantos e quaaes eram porem pera dello aver emformaçom quall deue disse e mandou da parte do dito Señor Rey e Joham affomso escripuam do almoxarifado da dita villa que lhe desse em escripto todos Ilos beens que el Rey ha no dito logo d'almodouuar pera el dito Juiz aver de fazer sobre ello aquello que lhe per el Rey he mamdado e que elle

\section{Traduction}

Enquête qui fut menée en la ville de Beja en raison des biens que le roi possède à Almodôvar du Campo d'Ourique - Commission du juge

Parce qu'il a été dit à Vasco Peres, [juge] pour le roi à Beja, que ledit Sire roi avait des biens dans ledit lieu d'Almodôvar et qu'ils n'étaient pas entretenus comme il convient et aussi parce qu'il n'avait pas d'information sûre quant à leur nombre et leur nature, [Vasco Peres] ordonna de la part du roi, pour être informé sur tout ceci, à João Afonso, notaire de l'almoxarifado ${ }^{1}$ de ladite ville

1. Cf. supra, note 2I; l'attribution d'une circonscription spécifique aux almoxarifes (qui exerçaient jusqu'alors leurs attributions dans les cadres préexistants, municipes ou seigneuries directes), finissant probablement par recouvrir tout le royaume, sur la base des principaux centres d'habitat, s'opère au cours du XIV e siècle à la faveur des nouveaux impôts généraux. 
emtemder por seu seruiço. E o dito escripuam satisfazendo ao dito mamdado do dito Juiz deu lhe em esta parte huuma escripta per ell de que o theor tall he :

Declaraçam dos beens que el Rey tem na dita villa d'almodouuar [énumération succinte des quelques possessions royales connues en-dehors des résultats de l'enquête]

A quall escriptura assy mostrada o dito juiz por servico del Rey e por milhor e mais compridamente aver emformaçorn e seer sabuudo em çerto se ha el Rey no dito logo mais beens que estes que assy som dados em escripto per o dito escripuaam. Esse som os dítos beens rreparados pella guisa que compre ou nom.

Porem o dito Juiz tomou sobre esta rrazom esta emquiriçorn que sse adiante segue a quall começou de tomar comigo gomçalle pereyra tabelliom del Rey em beja em nove dias de Janeyro da era de mill e quatroçemtos e quatorze annos pergumtamdo presente mim dito tabelliom estas testemunhas adiante escriptas pella guisa que sse adiante segue :

[...]

Item marinha hollalha molher que diz que foy de gomçallo beyraão laurador que foy del Rey na sua herdade que ella ha nos padroões jurada aos euamgelhos e pregumtada por a verdade de como e per que guisa lhe forom tomados os beens que ficarom per morte do dito seu marido e per quem lhe forom tomados Disse que ella testemunha sabe que moramdo ella testemunha e o dito seu marido na dita herdade del Rey que o dito seu marido fez seu testamemto em que fez sua alma herdeyra e que leijxava por seus testamemteyros Girall domimguez dos padroões e huum seu filho della testemunha que pagassem e comprissem seu testamemto pella. guisa que em ella era comtheudo segumdo diz que mais compridamente era comtheudo no dito testamemto

O quall diz que lhe fez e expreuco Gomez giraldez tabelliom do dito Iogo que
[Beja], qu'il lui mette par écrit tous les biens que le roi possède dans ledit lieu d'Almodôvar pour que ledit juge fasse à ce propos ce qui lui est ordonné par le roi et ce qu'il entend pour son service. Et ledit notaire, satisfaisant au mandat dudit juge, lui a donné un écrit rédigé par lui dont la teneur est ainsi :

Déclaration des biens que le roi a dans ladite ville (villa) d'Almodôvar [énumération succincte des quelques possessions royales connues en-dehors des résultats de l'enquête]... Ledit écrit ainsi montré, ledit juge, pour le service du roi et pour plus ample information et pour savoir sûrement si le roi a dans ledit lieu d'autres biens que ceux ainsi enregistrés par ledit notaire et si cesdits biens sont réparés convenablement, a ordonné l'enquête qui suit, que Gonçalo Eanes Pereira, tabellion du roi à Beja, a commencé à effectuer avec moi le 9 janvier de l'Ere I4I4 en interrogeant devant moi, susdit notaire, les témoins suivants de cette manière :

[...] [une douzaine de témoins décrit les biens du roi à Almodôvar puis la commission d'enquête se déplace au village de Padrões, où le ler témoin signale des irrégularités dans la garde des troupeaux royaux et le droit royal sur les biens en déshérence]

Item Marinha Olaia, veuve de Gonçalo Beirão qui fut laboureur du roi sur le domaine que celui-ci possède à Padrôes, ayant juré sur les évangiles et interrogée sur la façon dont - et pourquoi - lui furent pris les biens qui restèrent à la mort de sondit mari, déclara qu'elle-même et son mari demeuraient dans le domaine du roi quand son mari fit son testament - dans lequel il fit son âme héritière et nomma comme exécuteurs testamentaires Giraldo Domingues de Padrōes et un fils de la déposante pour qu'ils paient et exécutent son testament à la manière plus amplement précisée dans ledit testament. [Ce testament] a été fait et écrit par Gomes Giraldes, tabellion dudit lieu, qui réside actuellement hors du pays à cause d'une affaire assez grave pour qu'il n'ose reparaître. Et il advint que son mari mourut alors 
ora amda fora da terra por negoçio tall que ha per que nom ousa de pareçer no dito logo dalmodouuar $\mathrm{E}$ diz que cornteçeo que teemdo o dito tabelliom o dito testamento e amdamdo assy fora da terra como dito he que veo a desfalleçer per morte o dito seu marido della testemunha. Teemdo ao tempo da sua morte huuma ssoma de pam em que avia e poderia aver doze moyos de trigo e doze moyos de çeuada e dous quarteyros de cemteo segumdo seu emtemdimemto della testemunha e quatro bois darado com que laurauam e huuma ssoma de ovelhas Nom sse acorda ella testemunha quamtas eram.

Pero diz que guardaua louremço ouelheyro que dizem que ora amda nas ovelhas del Rey e bestas e huuma taça de prata de

85 huum marco e rroupa e alfayas e outras cousas per que viuiam bem na dita herdade como lauradores que eram.

E diz que como assy desfalleçeo per morte pode aver dez ou doze annos que por que ella testemunha nom mostrou nem podia mostrar o dito testamemto a gomçallo veegas comemdador do dito logo dos padroões por que tho tijnha o dito tabelliom como dito he que porem o dito comemdador per ssy e per seus homeens se apoderou de todos os ditos beens metemdosse em ssa casa com suas companhas que tragia e tomamdo os ditos beens e fechamdolhe a porta com cadeado per tall guisa que ella testemunha nom foy mais delles senhor.

E fezerom per tall guisa que sem ella tomauam e leuauam o dito pam assy pera semear huum alqueue que o dito seu 105 marido fezera na dita herdade del Rey como pera hu lhes prazia assy que lhe tomarom aquello que lhe prougue e leixarom aquello que quiserom e diz que per esta guisa lhe tomarom e leuarom 110 quamto tijnha.

E diz que nom sabe ella testemunha dizer todallas cousas que lhe tomarom por que diz que toda he fora de ssy com nojo do marido e do auer que perdeo pella guisa 115 que dito ha e de filhos que lhe outrossy que ledit tabellion se trouvait hors du pays avec le testament. Elle avait au moment du décès une quantité de grain équivalente, selon son estimation, à I2 muids de blé, I2 muids d'orge, 2 quartiers de seigle ${ }^{2}$ et 4 bœufs de labour avec lesquels ils labouraient et un nombre de moutons que le témoin a oublié. Et le berger (de moutons) Lourenço - dont on dit qu'il garde dorénavant les moutons du roi-garde des chevaux, une tasse d'argent d'un marc, des vêtements, des outils et d'autres choses grâce auxquelles ils vivaient bien sur ledit domaine en tant que laboureurs.

Ce décès s'étant produit il y a Io ou I2 ans, elle n'a jamais pu montrer ledit testament à Gonçalo Viegas commandeur dudit lieu de Padróes et celui-ci avec ses hommes s'empara de tous lesdits biens en les mettant dans sa maison et en fermant la porte avec une chaîne, de telle sorte que le témoin n'en a plus jamais été maître. Et, sans son consentement, ils prenaient ledit grain pour ensemencer une jachère que son mari avait faite dans ledit domaine du roi, selon leur bon vouloir, en prenant et laissant [de ce grain] au point d'en utiliser la totalité. [Estimation des autres biens confisqués]

Elle sait et est bien certaine que ledit commandeur lui prit, au titre de sa moitié et de la moitié de ladite jachère, 2 boeufs de labour, un très bon âne, la susdite tasse d'argent - dont on dit qu'il la garde encore dans sa demeure - et 9 livres équivalant à la moitié des vêtements et outils et tous lesdits moutons, en échange desquels il lui a rendu une somme dont elle ne se souvient plus. Il a réalisé deux fois le partage avec elle parce que l'on disait qu'il avait été mal fait, à cause de la façon dont il s'était payé et dont il avait pris le blé et l'orge selon son bon vouloir ; ledit commandeur disait qu'il prélevait tout ceci ainsi parce que son mari était mort intestat.

2. Moio $=$ muid, mesure de capacité valant 20 almudes (malgré l'étymologie commune, issue du latin à travers l'arabe $m u d d$ ) c'est-à-dire 360 à 520 litres selon les régions; le quartier, mesurant surtout le poids, est un quart de muid. 
morrerom assy que por esta rrazom se lhe seguio per tall guisa que nom tem ora outra cousa per que viua saluo se he huuma casa que comprou no dito logo dalmodouuar depois da morte do dito seu marido em que ora mora e aquilo que ganha afiar.

Pero diz que ella testemunha sabe e he bem çerta que o dito comemdador lhe tomou e leuou dous bois darado e huum muy boom asno e a dita taça de prata que dizem que aimda trage no paaço e noue liuras por ameatade da rroupa e alfayas e todas as ditas ouelhas por que ell the

130 tornou dinheiros dellas nom se acorda ella testemunha quamtos por a sua meatade e a meatade do dito alqueue.

O quall diz que partio com ella per duas vezes por que diziam que nom era bem partido partijmdoo ell como sse pagou E que do dito trigo e cevada tomou aquell que lhe prougue como quer que ell auia por partir com ella per meatade dizemdo o dito comemdador que todo

140 aquello que assy della leuou polla. guisa que he dito que o leuaua por que dizia que o dito seu marido morrera sem testamemto.

E diz que per o dito seu marido mam145 daua dar parte dos seus beens a huum moço de que ell era tutor e a quall ell deuia aquello que the ell mamdaua dar per rrazom da dita da dita tetoria que dele teuera e de seruiço que lhe fezera segumdo no dito testamemto mais compridamemte he comtheudo que o dito comemdador the nom quis dar ao dito moço nenhuuma cousa dos ditos beens pero que lhe foy dito e rrequirido e os ouue todos em ssy pella 155 guisa que he dito.

O qual testamento diz que lhe o dito gomez giralldez tabelliom daua depois que lhe assy forom tomados os ditos beens como dito ha e que ella testemunha o norn

160 quis tomar por que dizia que nom sabia que fazer dell E diz que o feito da verdade passou pella guisa que ella testemunha dito ha e quem mais nom sabe em esta parte $\mathrm{Eu}$ gomcalle annes pereyra esto escpreui.
Sondit mari, comme cela est stipulé dans son testament, avait fait donner une partie de ses biens à un jeune garçon dont il était tuteur, donation faite en raison de la tutelle et des services qu'il avait reçus de lui ; et ledit commandeur ne voulut rien donner desdits biens audit jeune homme, quoique cela lui ait été demandé, et il garda tout pour lui.

Ledit Gomes Giraldes, tabellion, lui donna ledit testament après que lesdits biens lui eussent été pris mais elle ne voulut pas le prendre, disant qu'elle ne savait qu'en faire. Et elle dit que la vérité s'est passée comme elle l'a raconté et qu'elle ne sait rien d'autre à ce sujet. Moi, Gonçalo Eanes Pereira [notaire], j'ai écrit ceci. 


\section{I04. \\ 2 avril 1385 \\ Délibération du conseil municipal de Loulé sur le banvin}

En échange du soutien du municipe contre le prétendant castillan au trône, le concelho réclame une réforme de la perception du droit de banvin et s'engage sur les biens communaux et par une taxe générale extraordinaire à garantir les revenus espérés pour le budget.

Source : Arquivo histórico da Câmara Municipal de Loulé, cote non fournie (éd. Actas das vereaçôes de Loulé, vol. I (Humberto Baquero MorENO, e.a. éd.), Porto, 1984, p. 67-69).

\section{Traduction}

$\mathbf{E}$ RA [DE] IIIIC XXIII ANOS

Do relego

Item dous dias do dicto mes era de mil quatrocentos viinte e tres anos em Loule nos

5 Paaços do Concelho seendo hi Alvaro Vaasquez Pimentel e Steve Anes juizes na dicta vila Stevam Vaasquez Rui Gomez Lourence Anes vereadores Lourenço Afonso procurador do Concelho Lourenço Afonso Lopo Stevez Gonçalo Vasquez Vasco Afonso seu hirmaao Martim Vasquez Vasco Lourenço cavaleiro Afonso Perez escudeiro Vasco Afonso neto de Vasco Estevez Afonso Nunez Vasco Lourenco de Beja Lourence Anes «Mil Libras» Joham

15 Afonso filho d'Afonso Anes Gonçalo Navarro Luis Estevez Diego Rodriguez Gonçalo Gonçallvez Joham Gonçallvez Vasque Anes Gonçalo Vasquez tabeliaes Alvaro Gomez Pero Rodriguez Joham Gonçallvez de Ludo Joham Fer-

20 nandez alcaide Martim Abegom Martim Afonso jenrro d'Andres Anes Afonso Vasques corrector Alvaro Afonso tirador dos direitos d'alcaidaria Steve Anes alfajeme Gonçalo Gonçallvez sapateiro Mateus Stevez Afonso Perez da

25 Porta de Faarom Joham Carrasco Joham Afonso Boalin (?) Gonçalo de Loule Lourenço Anes filho de Joham Martinz Afonso Dominguez jenrro do gamenho Joham Aguillar Andres Dominguez Martim Garrocho Pero Martinz besteiro Afonso Mendez Joham Valente e outros homens da dicta vila asi grandes como pequenos que nem hum nom contradise ergo Rui Gomez vereador e Lopo Stevez e Afonso Nunez que [barré : esto] non consentirom esto que todolos outros acordan, veendo os dictos homens boons que o Concelho pose seus capitelos perante o Mestre d'Avis noso Senhor antre
Ère de [mille] quatre cent vingt trois.

Au sujet du banvin ${ }^{1}$

Item 2 avril I423, à Loulé, au siège du concelho, en présence d'Alvaro Vasques Pimentel et Estevão Eanes juges de ladite ville (vila), Estevão Vasques, Rui Gomes, Lourenço Eanes conseillers municipaux (vereadores), Lourenço Afonso procureur du concelho, Lourenço Afonso, Lope Esteves, Gonçalo Vasques, Vasco Afonso son frère, Martim Vasques, Vasco Lourenço chevalier, Afonso Peres écuyer, Vasco Afonso petit-fils de Vasco Esteves, Afonso Nunes, Vasco Lourenço de Beja, Lourenço Eanes " mille livres ", João Afonso fils d'Alonso Eanes, Gonçalo Navarro, Luis Esteves, Diego Rodrigues, Gonçalo Gonçalves, João Gonçalves, Vasco Eanes, Gonçalo Vasques tabellions, Alvaro Gomes, Pedro Rodrigues, João Gonçalves de Ludo, João Fernandes alcaide, Martim Abegão, Martim Afonso gendre d'André Eanes, Afonso Vasques correcteur, Alvaro Afonso percepteur des droits d'alcaidaria ${ }^{2}$, Estevão Eanes armurier, Gonçalo Gonçalves savetier, Mateus Esteves, Afonso Peres de la porte de Faro, João Carrasco, João Afonso Boalin, Gonçalo de Loulé, Lourenço Eanes fils de João Martins, Afonso Domingues gendre du "séducteur», João Aguilar, André Domingues, Martim Garrocho, Pedro Martins arbalétrier, Afonso Mendes, João Valente et d'autres hommes de ladite ville tant grands que petits, dont aucun ne s'opposa [à la décision] (sauf Rui Gomes conseiller municipal,

1. Il a été décidé dans une session précédente que les revenus du banvin perçus par le municipe serviraient, au moins en partie, à financer les lourds frais d'envoi de deux délégués aux Cortes de Coimbra.

2. Cf. supra, note 17 ; l'entretien de l'alcaide (et de la forteresse qu'il gouverne) est assuré par l'assignation de certains revenus perçus dans le municipe, dits droits d'alcaidaria, pesant notamment sur les transactions. 
os quais era que non corresem moor relego na dicta vila que da em Faarom em Tavira e que pellas cortes que o dicto Senhor ha de fazer en Coinbra non livren esto e per a sa carta espiiceal lhi mandou recado que no dicto logo nas cortes veria seus [fol. I3 v.] capitelos e lhis faria mercee e porem vendo que os dictos Concelhos a dicta graça e mercee acordarom que o dicto relego se tome pello dicto Concelho e o ponham em elle que no corra e todo o que render se ponha em huma arca de duas chaves presente ho escripvam delle e que se tire com aqueles

50 direitos corno se tira no dicto logo de Faarom e de Tavira e se lhi o dicto Senhor outorgar a dicta graça gouvirom della como devem e se non tha quiser outorgar que elles outorgavam de lhi pagar a maioria pellos beens do dicto

55 Concelho. E outorgarom se non quiserem receber aos vereadores e procurador em despesa aquello que asii mais pagaren que se page pera elles todos e per todolos vezinhos e moradores de Loule e de seu termo e per cabeça e pellos

60 beens que cada hum ouver. Esto faziom por o que aviom [barré : fe] esforço que o dicto Senhor lhis fara em ello merce asi como fez aos dictos Concelhos porque delles recebe e recebeo e asperam em Deus que recebera delles

65 tamanho [barré : merce] serviço come dos dictos Concelhos. Testemunhas Gonçalo Rodriguez e Gonçalo Gonçallvez filho de Gonçalo Fernandez Vasco Afonso Carvalho e os sobredictos e outros. Eu Domingos Gonçallvez

70 tabeliom do dicto Senhor na dicta vila que esto escrevi e meu sinal fiz que tal he. [seing notarial]

Lourenço Afonso, Steuam vasquez, Lourenço Anes, Lourenço Afonso, Lourenço mjl libras, joham affonso, Afonso perez, gonçalo gonçallvez, joham gonçallvez.

E logo estando asii os dictos Alvaro Vaasquez e Steve Anes juizes diserom que elles outorgavam esto [barré : e o] suso escripto come vezinhos e nom come juizes. Testemunhas os sobredictos. Eu Domingos Gonçallvez tabeliom sto screvi.

Steue Anes, Aluaro vasquez
Lope Esteves et Afonso Nunes qui ne votèrent pas ce que tous les autres approuvèrent), lesdits bonshommes ont vu que le concelho avait établi ses chapitres auprès du Maître de l'Ordre d'Avis notre Sire, parmi lesquels figurait : que ne soit pas pratiqué dans ladite ville un banvin plus grand qu'à Faro et Tavira, que ceci ne soit pas décidé par les Cortes devant être tenues à Coimbra par ledit Sire et que [ledit Sire] avait accordé au concelho par charte spéciale qu'il verrait leurs chapitres et leur ferait merci au cours des Cortes; et voyant aussi que lesdits concelhos [de Faro et Tavira avaient reçu] ladite grâce et merci, ils décidèrent donc que : ledit banvin serait levé par ledit concelho..., que tout ce qu'il rapportera serait mis dans un coffre avec deux clés en présence du greffier du banvin, qu’il serait perçu avec les mêmes droits qu’à Faro et Tavira, que si ledit Sire accorde ladite grâce, ils jouiraient d'elle comme il convient et que s'il ne l'accorde pas, ils en paieraient la plus grande part sur les biens communaux. Ils décidèrent que si les conseillers et le procureur refusaient de recevoir en dépense [ $=\mathrm{d}$ 'inscrire au budget] la différence restant à payer, celle-ci serait payée par eux tous et par tous les " voisins » et habitants de Loulé et son territoire, par tête et sur la base des biens que chacun possède. Ils faisaient ceci parce qu'ils avaient l'espoir que ledit Sire leur fera grâce en cela comme il l'a fait auxdits concelhos [de Faro et Tavira] parce qu'il reçoit, a reçu et recevra - si Dieu le veut - de leur part le même soutien que de la part desdits concelhos.

Témoins : Gonçalo Rodrigues, Gonçalo Gonçalves fils de Gonçalo Fernandes, Vasco Afonso Carvalho et les susdits et encore d'autres. Moi, Domingos Gonçalves notaire dudit Sire dans ladite ville, j'ai écrit ceci et j'ai fait mon seing qui est celui-ci.

[Souscripteurs] Lourenço Afonso, Estevão Vasques, Lourenço Eanes, Lourenço Afonso [un autre], Lourenço "mille livres", João Afonso, Afonso Peres, Gonçalo Gonçalves, João Gonçalves.

Et aussitôt, en présence des susdits, Alvaro Vasques et Estevão Eanes, juges, dirent qu'ils décidaient ce qui est écrit ci-dessus en tant que voisins et non en tant que juges; ce dont sont témoins les susdits. Moi, Domingos Gonçalves, notaire, ai écrit ceci.

[Souscripteurs] Estevão Eanes, Alvaro Vasques. 